\title{
Application of TXRF in monitoring trace metals in particulate matter and cloud water
}

\author{
Khanneh Wadinga Fomba ${ }^{1}$, Nabil Deabji ${ }^{1,2}$, Sayf El Islam Barcha ${ }^{2}$, Ibrahim Ouchen ${ }^{2}$, El Mehdi Elbaramoussi ${ }^{2}$, \\ Rajaa Cherkaoui El Moursli ${ }^{2}$, Mimoun Harnafi ${ }^{3}$, Souad El Hajjaji ${ }^{2}$, Abdelwahid Mellouki ${ }^{4}$, and Hartmut Herrmann ${ }^{1}$ \\ ${ }^{1}$ Leibniz Institute for Tropospheric Research (TROPOS), Atmospheric Chemistry Department (ACD), \\ Permoserstraße 15, 04318, Leipzig, Germany \\ ${ }^{2}$ Faculty of Science, Mohammed V University in Rabat, 4 Avenue Ibn Battouta, B.P 1040, 10100 Rabat, Morocco \\ ${ }^{3}$ Scientific Institute, Mohammed V University in Rabat, Av. Ibn Battouta, B.P 703, 10106 Rabat, Morocco \\ ${ }^{4}$ Institut de Combustion Aérothermique Réactivité et Environnement, OSUC-CNRS, 1C Avenue de la Recherche \\ Scientifique, 45071 Orléans CEDEX 2, France
}

Correspondence: Hartmut Herrmann (herrmann@tropos.de)

Received: 9 November 2019 - Discussion started: 10 March 2020

Revised: 22 June 2020 - Accepted: 26 June 2020 - Published: 9 September 2020

\begin{abstract}
Trace metals in ambient particulate matter and cloud are considered key elements of atmospheric processes as they affect air quality, environmental ecosystems, and cloud formation. However, they are often available at trace concentrations in these media such that their analysis requires high-precision and sensitive techniques. In this study, different analytical methods were applied to quantify trace metals in particulate matter (PM) samples collected on quartz and polycarbonate filters as well as cloud water, using the Total reflection X-Ray Fluorescence (TXRF) technique. These methods considered the measurement of filter samples directly without and with chemical pretreatment. Direct measurements involved the analysis of PM samples collected on polycarbonate filters and cloud water samples after they are brought onto TXRF carrier substrates. The chemical treatment method involved the assessment of different acid digestion procedures on PM sampled on quartz filters. The solutions applied were reverse aqua regia, nitric acid, and a combination of nitric acid and hydrogen peroxide. The effect of cold-plasma treatment of samples on polycarbonate filters before TXRF measurements was also investigated.

Digestion with the reverse aqua regia solution provided lower blanks and higher recovery in comparison to other tested procedures. The detection limits of the elements ranged from 0.3 to $44 \mathrm{ng} \mathrm{cm}^{-2}$. $\mathrm{Ca}, \mathrm{K}, \mathrm{Zn}$, and Fe showed the highest detection limits of 44, 35, 6, and $1 \mathrm{ng} \mathrm{cm}^{-2}$, while As and Se had the lowest of 0.3 and $0.8 \mathrm{ng} \mathrm{cm}^{-2}$, respectively.
\end{abstract}

The method showed higher recovery for most trace metals when applied to commercially available reference materials and field samples. TXRF measurements showed good agreement with results obtained from ion chromatography measurements for elements such as $\mathrm{Ca}$ and K. Cold-plasma treatment did not significantly lead to an increase in the detected concentration, and the results were element specific. Baking of the quartz filters prior to sampling showed a reduction of more than $20 \%$ of the filter blanks for elements such as V, $\mathrm{Sr}, \mathrm{Mn}, \mathrm{Zn}$, and $\mathrm{Sb}$.

The methods were applied successfully on ambient particulate matter and cloud water samples collected from the Atlas Mohammed V station in Morocco and the Cape Verde Atmospheric Observatory. The obtained concentrations were within the range reported using different techniques from similar remote and background regions elsewhere, especially for elements of anthropogenic origins such as $\mathrm{V}, \mathrm{Pb}$, and $\mathrm{Zn}$ with concentrations of up to 10,19 , and $28 \mathrm{ng} \mathrm{m}^{-3}$, respectively. Enrichment factor analysis indicated that crustal matter dominated the abundance of most of the elements, while anthropogenic activities also contributed to the abundance of elements such as $\mathrm{Sb}, \mathrm{Se}$, and $\mathrm{Pb}$. The results confirm that TXRF is a useful complementary sensitive technique for trace metal analysis of particulate matter in the microgram range as well as in cloud water droplets. 


\section{Introduction}

Aerosols play an important role in atmospheric processes as they control the atmospheric composition. Aerosol particles (particulate matter) provide surfaces for the adsorption of gases and atmospheric species, thereby, serving as a catalyst for heterogeneous chemical reactions. Particulate matter is the main source of condensation nuclei on which cloud droplets are formed. Clouds affect the climate and weather and are the source of precipitation and, hence, water in arid ecosystems. However, these impacts are closely related to their chemical compositions, amongst which is their elemental composition. Trace metals in aerosols and cloud water play an important role in defining aerosol and cloud physicochemical properties as they control key reactions within these media. Aerosol trace metals control atmospheric oxidation capacity and serve as catalysts for chemical reactions that influence radical budgets and atmospheric chemical reaction rates (Losno, 1999; Herrmann et al., 2015). They provide important hints to the sources of particulate matter emission and their fate. Studies have shown that aerosol emission sources have specific profiles with certain characteristic trace metals, making elemental analysis an important tool for particulate matter source apportionment studies (VanCuren et al., 2012; Zhang et al., 2014; Miller et al., 2019), and in the quantification of PM source contributions (Harrison et al., 2012; van Pinxteren et al., 2016; Pacyna et al., 2007). Moreover, elemental analysis of cloud water provides information on cloud condensation nuclei types (Bianco et al., 2017; Ma et al., 2004), possible in-cloud heterogeneous reactions (Passananti et al., 2016; Ervens, 2015), such as the oxidation of S(IV) to sulfate (Harris et al., 2013), or trace metal influence on the $\mathrm{HO}_{x}$ budget due to the Fenton reaction (Deguillaume et al., 2005). However, an assessment of their levels in mountain regions in the Saharan region where a combination of different natural and anthropogenic sources may control their abundance is lacking.

Evaluating the trace metal composition and the metals' effects in these media require sensitive techniques that can quantify the typically low concentration levels of metals in these media, over a wide range of particle sizes. Studies have shown that although ICP-MS (inductively coupled plasma mass spectrometry), ICP-OES (inductively coupled plasma optical emission spectroscopy), and AAS (atomic absorption spectroscopy) are sensitive techniques, most often a larger amount of sample substance is necessary for adequate sample preparation and handling (Bennun and Sanhueza, 2010). This makes the application of alternative techniques such as total reflection X-ray fluorescence spectrometry (TXRF) attractive in the analysis of particulate matter with very little mass, (typically in the microgram range) in comparison to the other techniques (Bulska and Ruszczyńska, 2017). TXRF is a highly sensitive surface technique, which is a variation in the energy-dispersive X-ray fluorescence (XRF) (Kchih et al., 2015), designed such that the X-ray beam is incident at a glancing angle on a polished substrate to enable a total internal reflection of the incident beam at its surface. This setup improves on the spectral background, increases the excitation frequency of the elements, and enhances the element sensitivity compared to conventional XRF methods (Bertin, 1975; Klockenkämper and von Bohlen, 2014a). However, to obtain the advantages offered by TXRF, only a very thin film of the analyte is required on a polished surface of which quartz and sapphire substrates are often used. TXRF is applicable to soil, biological, water, and sediment samples (Towett et al., 2013; Bilo et al., 2014; Stosnach, 2005). Due to its enhanced sensitivity, TXRF can easily be applied to cloud samples, as these matrices provide optimum conditions for the realization of a thin film on the carrier surface. As with other established methods for cloud water analysis such as ICPMS, ICP-OES, and AAS (Xu et al., 2018) and also ion chromatographic techniques for cations and transition metal ions (Fomba et al., 2015), sample preparation steps are few and fast.

As particulate matter is typically sampled on filter material, the application of this technique on aerosol samples requires different sampling and sample preparation methods to obtain the requisite geometry of the sample on the polished substrates to make use of the expected enhanced sensitivity. Recently, Prost et al. (2017) showed that by direct sampling of aerosol particles on polished quartz substrates greased with a jelly organic paste and subsequent cold-plasma oxidation of the paste, it is possible to perform TXRF analysis directly on such substrates and obtained measurable concentrations in the picogram per cubic meter $\left(\mathrm{pg} \mathrm{m}^{-3}\right)$ range. However, the limitation of this method lies in the difficulty in controlling the thickness of the particles on the film especially in highly polluted regions where PM loading is high, which could lead to multiple layers of particulate matter on the carrier. Studies have also shown the applicability of TXRF on particulate matter sampled on polycarbonate filters (Wagner and Mages, 2010; Bilo et al., 2018; Motellier et al., 2011), which for some cases were subsequently combusted via coldplasma ashing and not combusted in others, before measurement. Despite the advantage of the cold-plasma ashing step in reducing the thickness of the sample layer and attenuation of the signal, the risk of contamination and variable recovery have been reported (Woelfl et al., 2003), making its applicability for aerosol samples unclear. Different sample preparation methods have been evaluated on PTFE membranes and polycarbonate filters, which are commonly used for aerosol sampling (De La Calle et al., 2013). However, the applicability of TXRF on aerosol particles collected on quartz fibers is not well investigated (Okuda et al., 2013). This is mainly because of the high metal blank concentrations often obtain in this material making it less attractive to other materials such as Teflon or polycarbonate (Upadhyay et al., 2009; Buck and Paytan, 2012). Besides, the thickness of the quartz filters increases the attenuation of the X-ray signals when measured directly (Bertin, 1975), requiring thinner filters than those 
currently commercially available. However, in comparison to other standard techniques such as ICP-MS and ICP-AES, digestion methods of quartz filters suitable for TXRF analysis are not known, especially as particles must not be fully digested in acids to obtain the required sensitivity. As many air quality monitoring networks sample aerosol particles on quartz filters due to the feasibility of using the same filter sample for many analyses including elemental and organic carbon and ionic contents of the particulate matter, the development and applicability of analytical methods with quartz filters need further examination. This reduces energy consumption through the deployment of fewer monitoring devices, as well as the cost of acquisition of many collectors, which is a challenge for monitoring networks in developing countries.

In the present study, different digestion procedures have been examined on different batches of quartz fiber filters to assess the most preferred protocol that offers less matrix effect for quantification of trace metals using TXRF. In addition, the role of the baking of filters on their blank concentration has been evaluated. Furthermore, the use of plasma ashing of polycarbonate filters has been reassessed to evaluate if this procedure could be redundant for samples with high particulate matter loading. The methods were applied to aerosol samples collected at the Atlas Mohammed V (AM5) observatory and the Cape Verde Atmospheric Observatory (CVAO) during intensive field studies lasting 2 to 3 weeks. The technique was also applied to quantify elemental concentrations in cloud water samples from the AM5 site. The results provide the first assessment of trace metal levels at the high remote Atlas mountain regions in northern Africa and activities that contribute to their abundance in the region.

\section{Material and methods}

\subsection{Instrument}

Trace metals were quantified using a benchtop S2 PICOFOX TXRF spectrometer (Bruker AXS Microanalysis $\mathrm{GmbH}$, Germany). The instrument is equipped with a Mo anode metal-ceramic X-Ray tube having a multilayer monochromator and an XFlash ${ }^{\circledR} \mathrm{Si}$ drift detector, which has an area of $30 \mathrm{~mm}^{2}$ with energy resolution $<160 \mathrm{eV}$ for the $\mathrm{Mn}-\mathrm{K}_{\alpha}$ line. The Mo- $\mathrm{K}_{\alpha}$ excitation was $17.5 \mathrm{keV}$, and the instrument was operated at $750 \mu \mathrm{A}$ and $50 \mathrm{kV}$. The typical measurement time was $500 \mathrm{~s}$, and the treatment of the X-ray spectra, analysis of elemental concentration, and deconvolution of spectra fluorescence peaks were performed using the SPECTRA 6.2 software.

\subsection{Reagents and materials}

Internal standards consisting of gallium (Ga) inductively coupled plasma (ICP) standard solution with the concentration of $1000 \mathrm{mg} \mathrm{L}^{-1}$ (Merck, Germany) and yttrium (Y)
ICP standard solution with the concentration of $1000 \mathrm{mg} \mathrm{L}^{-1}$ (Roth, Germany) mixed in the ratio $1: 1$ was used. Highpurity water deionized with Milli-Q water purification system (Millipore) was used for the dilution of standards. Hydrogen peroxide $30 \%$ (Th.Geyer, Germany) solution was used for filter digestion procedures. Quartz glass discs with a $30 \mathrm{~mm}$ diameter and a thickness of $3 \mathrm{~mm} \pm 0.1 \mathrm{~mm}$ were applied as TXRF sample carriers. They were cleaned using different cleaning solutions in three subsequent steps, involving boiling in $10 \%$ conc. $\mathrm{HCl}$ (supra-quality, ROTIPURAN, Roth Germany) and $15 \%$ conc. $\mathrm{HNO}_{3}$ (supra-quality, ROTIPURAN, Roth Germany) and in a detergent solution (RBS 50, $4 \%$ concentrated). Between each solution, the carriers were rinsed with ultrapure water and treated in an ultrasonic bath for $30 \mathrm{~min}$. After cleaning, they were dried in an oven for about $3 \mathrm{~h}$. Sample carriers were, thereafter, siliconized by $5 \mu \mathrm{L}$ of a silicon solution in isopropanol (Merck, Germany) to avoid the spreading of the samples on the surface of the carriers.

\subsection{Reference material}

To compare the measured values with those observed with other techniques, calibrate the instrument, and validate sample preparation methods, various commercial standard reference materials were used. The NIST 2783 Standard Reference Material (SRM) air particulate matter sample and a multielement standard solution (lot N15521), with a concentration of $100 \mathrm{mg} \mathrm{L}^{-1}$ for 28 elements (23 detectable with the PICOFOX, excluding lighter elements such as $\mathrm{Li}, \mathrm{B}, \mathrm{Be}, \mathrm{Na}$, and $\mathrm{Mg}$ ) were purchased from Sigma Aldrich, Germany, and C.P.A. Ltd, Bulgaria (CPA), respectively. The NIST 2783 is an air particulate matter sample that simulates particles with an aerodynamic equivalent diameter of $2.5 \mu \mathrm{m}\left(\mathrm{PM}_{2.5}\right)$ deposited on polycarbonate filter membranes.

\subsection{Particulate matter and cloud water sample collection}

Particulate matter and cloud water samples were collected at the AM5 observatory in Michlifen, Morocco, and the CVAO in São Vicente, Cabo Verde.

The AM5 site is located in the middle of the Atlas Mountains, $2000 \mathrm{~m}$ a.s.l., in a predominantly hilly site $\left(33^{\circ} 24^{\prime} 22.2^{\prime \prime} \mathrm{N} 5^{\circ} 06^{\prime} 12.0^{\prime \prime} \mathrm{W}\right)$ that experiences frequent changes in the wind direction. It lies in a remote region about $20 \mathrm{~km}$ away from the nearest urban cities. The aerosol particles were collected using a high-volume sampler (DIGITEL, DHA-80, Switzerland) with a flow rate of $500 \mathrm{~L} \mathrm{~min}^{-1}$, equipped with a $\mathrm{PM}_{10}$ inlet. The collector was mounted on the roof of a container with an inlet height of about $5 \mathrm{~m}$ above the ground. The aerosol particles were collected on quartz fiber filters (Munktell, MK 360) in a $12 \mathrm{~h}$ day-night sampling routine. The sampling routine was set to identify differences between the transport of day and night emissions 
to this remote site. Sampling was done for 3 weeks between August and September 2017. Cloud water was sampled using a Caltech Active Strand Cloud water Collector (CASCC2) (Demoz et al., 1996) on the roof of the container. This was done whenever the mountain was covered with clouds. The sampling time varied depending on the duration of the cloud coverage, and one sample was collected per cloud event. The cloud water volume ranged between 30 and $150 \mathrm{~mL}$, and the samples were frozen immediately after sampling. Although freezing may induce the formation of insoluble carbonates, e.g., $\mathrm{CaCO}_{3}$, in the sample as indicated by Cherif et al. (1998), the freezing helps prevent microbial decomposition of organics and subsequent chemical reactions in the samples. For the collection of the cloud water blanks, the CASCC2 strands were cleaned with deionized water and ethanol, and deionized water was thereafter sprayed onto the cleaned strands, and the resulting droplets were collected and used as blanks.

The CVAO is located $30 \mathrm{~m}$ offshore the east coastline of the Sao Vicente island of Cabo Verde. It experiences predominantly northeast winds, providing an ideal location for monitoring long-range transport of particulate matter from Africa and Europe. At the CVAO, a five-state Berner impactor with a sampling rate of $75 \mathrm{~L} \mathrm{~min}^{-1}$ also equipped with a $\mathrm{PM}_{10}$ inlet was deployed for the collection of the aerosol particles. With the impactor system, the air is pumped through nozzles of defined diameter, and particulate matter is deposited onto the impaction surface due to their inertia. The deployed Berner impactor has five stages with decreasing nozzle diameter stacked on top of each other enabling the collection of particles of different sizes on the impaction plates. The cutoff of the various stages (St.) was 50-140 nm, $140-420 \mathrm{~nm}$, $420-1200 \mathrm{~nm}, 1200-3500 \mathrm{~nm}$, and $3.5-10 \mu \mathrm{m}$, corresponding to St. 1 to St. 5, respectively. The collector was mounted at the top of a $30 \mathrm{~m}$ tall tower, and particles were collected on polycarbonate membranes placed beneath the nozzles of the respective impaction plates in a $24 \mathrm{~h}$ sampling routine for 2 weeks in January 2017. During the sampling, blank filters were collected by exposing the sampler to the ambient with no air sucked through the filters. This field blank sample collection procedure was done for both the Berner impactor and the DIGITEL sample collection.

\subsection{Sample preparation}

\subsubsection{Bulk aerosol samples}

The quartz fiber filters from the DIGITEL were weighed before and after sampling to determine the aerosol particulate mass collected on the filters. After weighing the filters, three spots of $8 \mathrm{~mm}$ in diameter (ca. $0.5 \mathrm{~cm}^{2}$ each) were punched out of the filters using a ceramic puncher. The punched-out filters were further cut into small pieces using ceramic scissors and placed into a $10 \mathrm{~mL}$ acid-cleaned Teflon bomb. A total of $1.5 \mathrm{~mL}$ of concentrated acids of $\mathrm{HCl}$ and $\mathrm{HNO}_{3}$ in the ratio $1: 3$ was added into the digestion bomb which was then treated in a microwave for $2 \mathrm{~h}$. The digestion was done with a high-pressure digestion device with $10 \mathrm{~mL}$ bombs (MARS 6, CEM GmbH, Kamp-Lintfort, Germany). The main objective of digestion was to wash the particles off of the surface of the filters and have them in a homogenous solution that is representative of the sample and can be easily quantified. This is because typical filters are too thick to be directly analyzed by TXRF. After cooling, the solution was stirred and aliquots $(50 \mu \mathrm{L})$ of the digested solution taken and pipetted onto polished TXRF quartz carrier $(3 \mathrm{~cm}$ diameter and $3 \mathrm{~mm}$ thickness). The aliquots were pipetted in a series of $25 \mu \mathrm{L}$ each on a siliconized quartz glass sample carrier to ensure confinement of the samples within a diameter of $1 \mathrm{~cm}$ for an effective excitation of the sample. $\mathrm{Ga}+\mathrm{Y}$ was added to the solution, providing internal standards for the quantification of the elements. The solution was allowed to evaporate on a heating plate for $10 \mathrm{~min}$ at $80^{\circ} \mathrm{C}$. For these measurements, quartz TXRF sample carriers were used, and their surfaces siliconized as previously described. Blank samples were also analyzed with a similar procedure, and the field samples were subsequently blank corrected.

The elemental concentrations of blank filters from different batches (MK 360 lot \#, 3194, 3169, 3236, 910952, $2749219)$ were investigated using different digestion procedure. Three digestion procedures were tested including nitric acid, reverse aqua regia $\left(3 \mathrm{HNO}_{3}: 1 \mathrm{HCl}\right)$, and $3 \mathrm{HNO}_{3}$ : $1 \mathrm{H}_{2} \mathrm{O}_{2}$ solution. They were applied to field samples to evaluate the method with a higher recovery. In addition, the effect of pre-firing of the filters on their blank values was performed.

\subsubsection{Size-resolved samples}

In a clean bench, a defined area (ca. $0.5 \mathrm{~cm}^{2}$ ) of the polycarbonate filters collected with the five-stage cascade impactor was cut out. The cut-out filter area contained six, three, two, one, and one, impaction spots corresponding to filters of St. 1 to St. 5, respectively. The cutoff filter pieces were placed on polished quartz carrier substrates and spiked with $5 \mu \mathrm{L}$ of concentrated nitric acid, to enable a planar film on the carrier surface. In addition, $\mathrm{Ga}+\mathrm{Y}$ was added as an internal standard onto the sample. However, quantification was done with $\mathrm{Ga}$, while $\mathrm{Y}$ was used as a reference. The solution was allowed to evaporate on a heating plate for $10 \mathrm{~min}$ at $80^{\circ} \mathrm{C}$, and after cooling, the sample was measured. A similar procedure was performed for field blank filters. To investigate the effect of cold-plasma treatment on the signal recovery, the prepared samples were measured before and after coldplasma treatment. The samples were treated in a cold-plasma asher (Technics Plasma GmbH, Kirchheim, Germany) operated at an oxygen pressure of 1 mbar using high-purity oxygen $(99.99 \%)$, at a microwave power of up to $300 \mathrm{~W}$ for $4 \mathrm{~h}$. 


\subsubsection{Cloud water samples}

Cloud water samples were defrosted and $25 \mu \mathrm{L}$ of the sample pipetted twice onto polished siliconized quartz carriers. The samples were further spiked with the $\mathrm{Ga}+\mathrm{Y}$ internal standard solution and allowed to evaporate on a hotplate as explained above for the other samples. The dry carrier was, thereafter, transferred to the instrument for measurements. The same procedure was carried out for field blanks.

\subsubsection{Standards}

Similar methods to those used on field samples were applied to the standard reference material. The NIST SRM 8785 sample was prepared by microwave digestion with a similar procedure as the bulk aerosol samples. The NIST 2783 SRM was prepared using the direct measurement procedure by punching out a $0.5 \mathrm{~cm}^{2}$ area of the filter and placing it on a quartz carrier, followed by subsequent spiking with an internal standard and $5 \mu \mathrm{L}$ of concentrated nitric acid similar to the procedure used for the size-resolved samples. The multielement standards were directly pipetted onto the carriers and allowed to evaporate as was done with the cloud water samples. The recoveries of the elements from the sample preparation methods were evaluated by comparing the obtained values with the reference certified values.

\subsection{Measurements}

All samples were measured thrice using a measurement time of $500 \mathrm{~s}$; after which, it was rotated at an angle of $90^{\circ}$ and remeasured. The measurements at the different angles were to ensure that in the cases where the sample diameter is bigger than the recommended $10 \mathrm{~mm}$, the rotation will enable the sample out of the center to be measured and as such improve the probability of analyzing the entire sample effectively. The maximum values of the measurements were then used for subsequent analysis. Typically, for samples whose diameter is $<10 \mathrm{~mm}$, there is a high reproducibility of the measurements and a coefficient of variability of less than $5 \%$ within a $95 \%$ confidence interval. However, for samples with larger areas on the carriers the variation can attain $20 \%$. Typically about 18 elements or more were analyzed based on their abundance in the PM and cloud water field samples. Si was not considered in these measurements due to the utilization of quartz filters and sample carriers. The lower limit of detection for the given media was estimated from the reference samples according to Klockenkämper (Klockenkämper and von Bohlen, 2014b), LLD $=3 C \times \sqrt{2 N_{\text {back }}} / N_{\text {net }}$, where $C$, is the concentration of element in the blank sample; $N_{\text {net }}$ and $N_{\text {back }}$ are the net and background count rate of the fluorescent X-ray signal, respectively. The method detection limit (MDL) for the given matrices was estimated as $3 \sigma_{\text {blank }}$, where $\sigma_{\text {blank }}$ is the standard deviation of the element concentration in the blank filter.

\section{Results and discussions}

\subsection{Reference material}

The reference materials NIST (SRM) were measured using the S2 PICOFOX, and the values obtained were compared with the certified values provided by NIST. Figure 1 shows the plot of the determined trace metal concentrations in the standards and the certified values. The determined concentrations showed good agreement with the certified values within an $8 \%$ error margin, indicating that measurements with the direct filter sample preparation method without microwave digestion is a reliable method for analyzing atmospheric particulate matter collected on thin polycarbonate filter membranes.

Similar results were obtained with the CPA multielement standard solution, revealing good agreement between the measured and the certified values. The standard was prepared by direct pipetting of the solution on the quartz carrier surface. For elements such as $\mathrm{Al}, \mathrm{As}, \mathrm{Ti}, \mathrm{Cr}, \mathrm{Cu}, \mathrm{Mn}$, and $\mathrm{Sb}$ the certified concentrations were slightly higher than the measured values, while for elements such as $\mathrm{Ba}, \mathrm{Ca}, \mathrm{Co}, \mathrm{K}, \mathrm{Ni}$, $\mathrm{Pb}, \mathrm{Sr}$, and $\mathrm{Zn}$ the measured values were slightly higher than the certified values. As observed in Fig. 2, despite the variation obtained between the individual runs of the measurements, the measured mean values were often within $1 \%$ of the certified values. This result further confirms the strength of TXRF in quantifying trace elements in thin membranes and liquid samples, without further sample preparation also reported for other matrices (von Bohlen and Fernández-Ruiz, 2020).

Quartz filter was used as reference material for the microwave digestion method as described above. In principle, for analysis with TXRF, complete digestion of the filters is not essential. However, the resulting particles have to be fine and less than $10 \mu \mathrm{m}$ to avoid adsorption effects and ensure reliable measurements. Hence, for particulate matter collected on thick filter substrates, dissolution of the particles is necessary prior to TXRF measurements. In the absence of certified metal concentrations on quartz fiber filters, an $8 \mathrm{~mm}$ diameter area of a blank filter was punched out and spiked with $100 \mu \mathrm{L}$ of the CPA multielement standard. After allowing them to dry for $30 \mathrm{~min}$ at $70^{\circ} \mathrm{C}$ on a hotplate, they were transferred into PTFE digestion bombs and treated with reverse aqua regia solution in a microwave. The recoveries of the high-pressure digestion treatment are presented in Table 1 . The recoveries ranged from $72 \%$ to $118 \%$ except for $\mathrm{Al}$, where the recovery was $55 \%$. The high recoveries were obtained for $\mathrm{Ba}, \mathrm{Pb}, \mathrm{Mo}$, and $\mathrm{Ca}$, while the lower recoveries were observed for As, Ti, $\mathrm{Sb}, \mathrm{Ag}$, and Se. This is most likely because signals of these elements overlapped with other elements of the standard solution, leading to high uncertainties in their quantification. This was the case with Mo and $\mathrm{S}, \mathrm{Ca}$ and $\mathrm{Sb}, \mathrm{Ti}$ and $\mathrm{Ba}$, and $\mathrm{Pb}$ and $\mathrm{As}$. The low recovery of $\mathrm{Al}$ from the filter indicates that the digestion process could not 

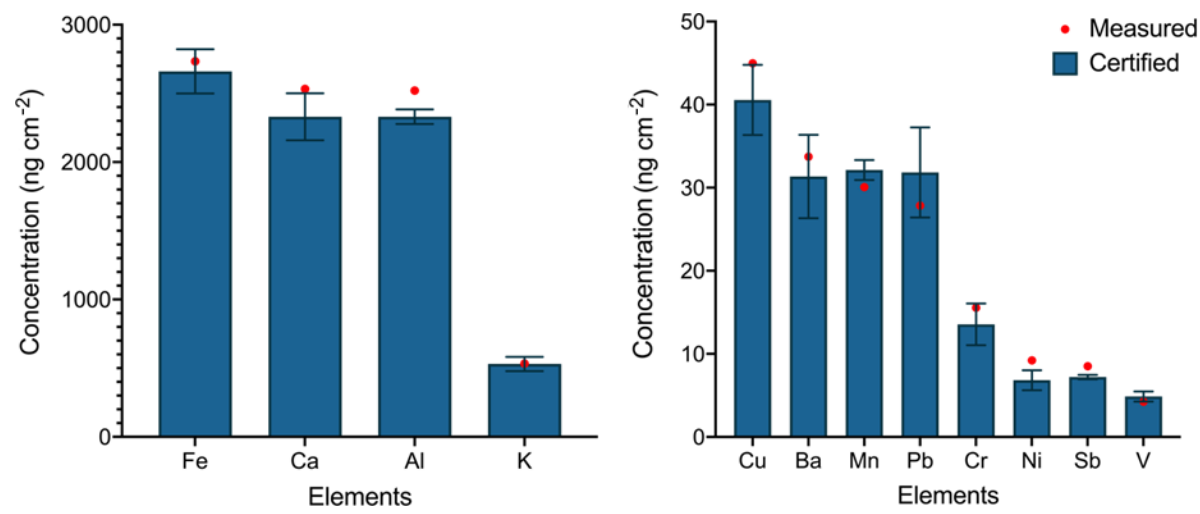

Figure 1. Plot of measured metal concentrations of NIST SRM 2783 sample using direct sample preparation method without microwave digestion.

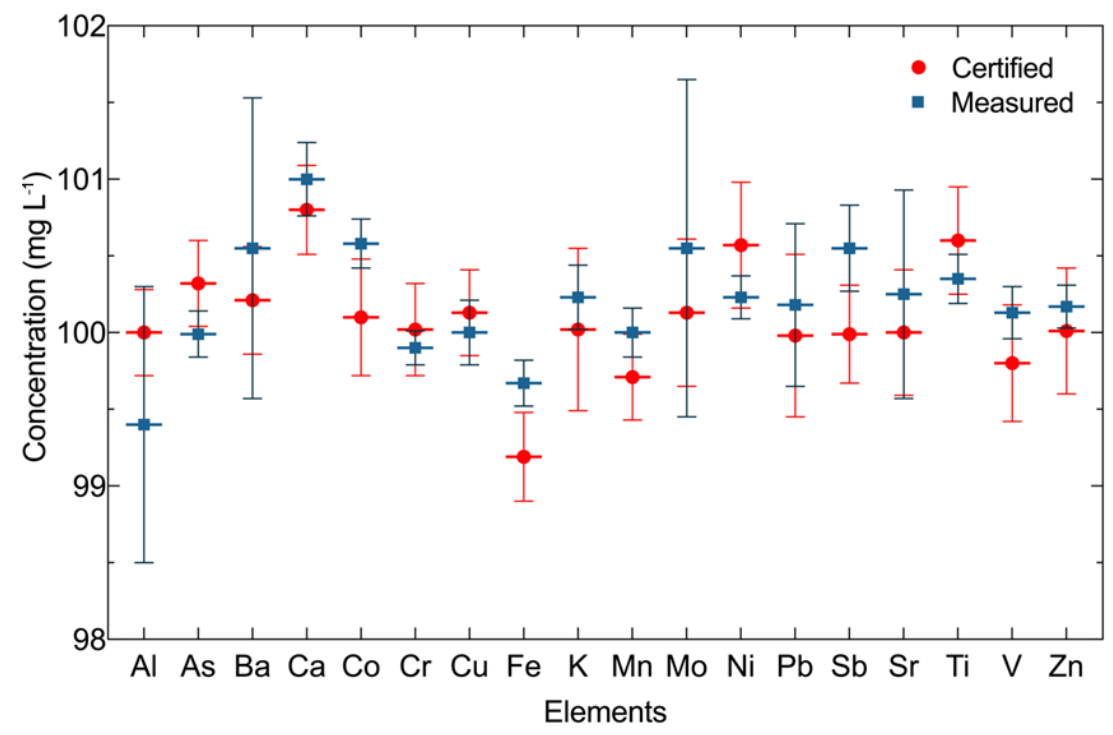

Figure 2. Good agreement observed between measured and certified values of metals in the multielement standard solution.

completely extract the $\mathrm{Al}$ from the quartz filter. For the field samples, the values of Al were not adjusted with the percentage of the recovery, as the sample composition and adhesion of the particles on the filters are different, which could lead to an overestimation of the values. Contrary to other studies whereby Mo could not be determined with a Mo-anode TXRF instrument (Stosnach, 2005), the result from this CPA standard illustrates that using the L lines, Mo can be quantified within a given uncertainty with the S2 PICOFOX instrument. The recoveries of the other elements were above $90 \%$. This indicates that the dissolution method can provide reliable results, especially if all the particles are effectively dissolved or miscible in the solvent.

To compare the direct analysis method and the microwave digestion method, the SRM 2783 was prepared using both methods and measured using the S2 PICOFOX. As shown in Fig. 3, good agreement in the determined elements was observed between the samples prepared by both methods.
For elements such as $\mathrm{Ca}, \mathrm{Fe}$, and $\mathrm{Al}$, the microwave digestion method revealed a higher recovery in comparison to the direct analytical method without digestion with a difference of about $8 \%$. The differences between the two methods were much lower for the other elements ranging from $2 \%$ to $5 \%$. Comparatively, the microwave digestion method, in general, revealed a higher recovery than the direct measurement method for particles on polycarbonate membranes with difference varying between $2 \%$ and $8 \%$ depending on the element. It is worth noting that the SRM 2783 is an urban particulate matter reference containing a different mineralogical property compared to soil samples or sediments. Hence, the observed difference in some elements may vary when other particulate matter types are measured, and this should be taken note of when comparing the results of this study with other studies. 


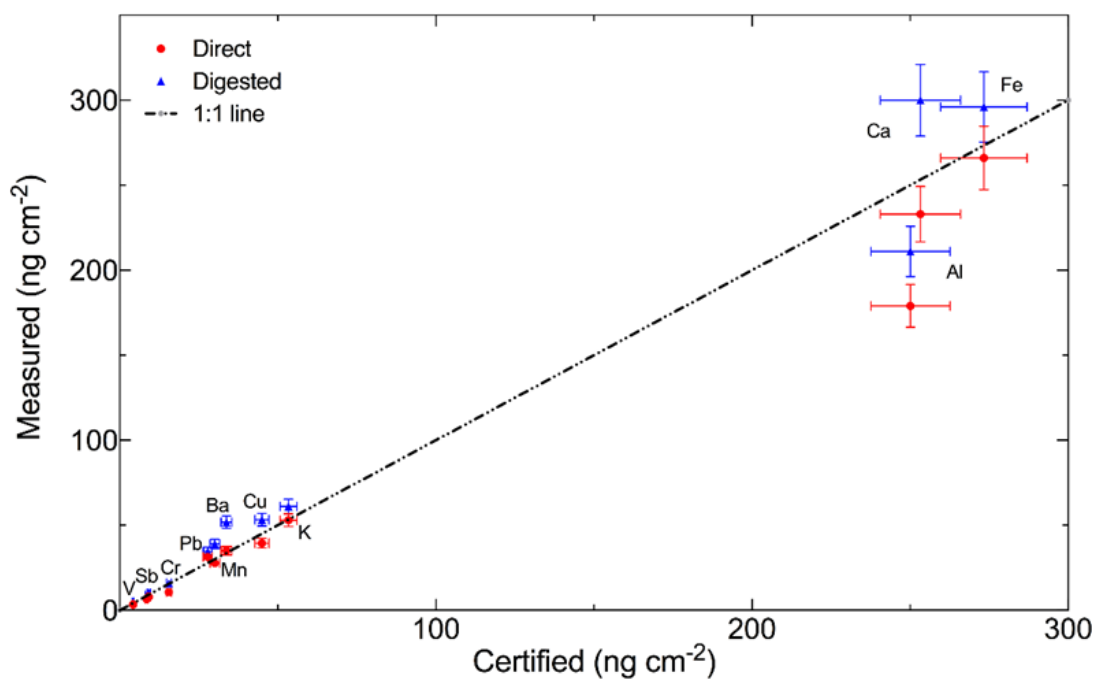

Figure 3. Comparison of microwave digestion and direct analysis method using SRM 2783 samples on polycarbonate membranes.

Table 1. Recoveries of the tested digestion procedures for quartz filters spiked with $10 \mu \mathrm{g}$ CPA multielement solution $(n=3)$.

\begin{tabular}{lrr|rrl}
\hline \multirow{2}{*}{ Elements } & \multicolumn{2}{c}{ Measured $(\mu \mathrm{g})$} & \multicolumn{2}{|c}{ Certified } & \multirow{2}{*}{ Recovery $(\%)$} \\
\cline { 2 - 5 } & Mean & SD & Mean & SD & \\
\hline $\mathrm{Al}$ & 5.47 & 0.94 & 10.00 & 0.28 & $54.7 \pm 17.2$ \\
$\mathrm{~K}$ & 10.01 & 0.21 & 10.02 & 0.53 & $99.9 \pm 2.1$ \\
$\mathrm{Ca}$ & 11.16 & 0.24 & 10.00 & 0.29 & $111.6 \pm 2.2$ \\
$\mathrm{Ti}$ & 7.97 & 0.16 & 10.04 & 0.35 & $79.5 \pm 2$ \\
$\mathrm{~V}$ & 9.43 & 0.17 & 10.01 & 0.38 & $94.2 \pm 1.8$ \\
$\mathrm{Cr}$ & 9.61 & 0.11 & 10.00 & 0.30 & $96.1 \pm 1.1$ \\
$\mathrm{Mn}$ & 9.71 & 0.16 & 10.00 & 0.28 & $97.1 \pm 1.7$ \\
$\mathrm{Fe}$ & 9.19 & 0.15 & 10.00 & 0.29 & $91.9 \pm 1.6$ \\
$\mathrm{Co}$ & 9.88 & 0.16 & 10.03 & 0.38 & $98.5 \pm 1.6$ \\
$\mathrm{Ni}$ & 10.57 & 0.14 & 10.00 & 0.41 & $105.7 \pm 1.3$ \\
$\mathrm{Cu}$ & 9.23 & 0.21 & 10.00 & 0.28 & $92.3 \pm 2.3$ \\
$\mathrm{Zn}$ & 9.98 & 0.14 & 10.00 & 0.41 & $99.8 \pm 1.4$ \\
$\mathrm{As}$ & 7.23 & 0.15 & 10.03 & 0.28 & $72.1 \pm 2.1$ \\
$\mathrm{Se}$ & 7.81 & 0.17 & 10.02 & 0.62 & $78 \pm 2.2$ \\
$\mathrm{Sr}$ & 13.66 & 1.68 & 10.03 & 0.41 & $136.2 \pm 12.3$ \\
$\mathrm{Mo}$ & 12.83 & 1.49 & 10.01 & 0.54 & $128.1 \pm 11.6$ \\
$\mathrm{Ag}$ & 7.44 & 0.76 & 10.01 & 0.29 & $74.3 \pm 10.2$ \\
$\mathrm{Cd}$ & 11.27 & 0.82 & 10.01 & 0.41 & $112.6 \pm 7.3$ \\
$\mathrm{Sb}$ & 8.88 & 0.28 & 9.99 & 0.32 & $88.9 \pm 3.2$ \\
$\mathrm{Ba}$ & 12.00 & 0.98 & 10.04 & 0.35 & $119.6 \pm 8.2$ \\
$\mathrm{Tl}$ & 9.65 & 0.16 & 10.00 & 0.28 & $96.5 \pm 1.6$ \\
$\mathrm{~Pb}$ & 11.84 & 0.53 & 10.02 & 0.53 & $118.1 \pm 4.5$ \\
$\mathrm{Bi}$ & 10.97 & 0.15 & 9.99 & 0.29 & $109.8 \pm 1.4$ \\
\hline & & & & &
\end{tabular}

\subsubsection{Filter blanks and method recovery}

The blank values of both the polycarbonate membranes and the quartz fiber filters were determined and the lower limit of detection of the elements on these filters evaluated. Table 2 summarizes the absolute elemental blank concentrations of the filters as well as the lower limits of detection and the method detection limits. The blank concentrations of the elements observed in the filters ranged from $60 \mathrm{pg}$ to $55 \mathrm{ng}$ (ca. 0.1 to $26 \mathrm{ng} \mathrm{cm}^{-2}$ ) for the polycarbonate filter membranes and from $300 \mathrm{pg}$ to $566 \mathrm{ng}$ (ca. 0.3 to $44 \mathrm{ng} \mathrm{cm}^{-2}$ ) for the quartz fiber filter. This value varied between the delivery batches. Despite the variation in the concentrations per delivery batch, the range of the concentrations was typically less than a factor of 2 for most of the elements. The method detection limit for the quartz filters was higher than that observed for the polycarbonate membranes. In comparison to detection limits and blank concentrations reported from other digestion procedures using combinations of $\mathrm{HNO}_{3} / \mathrm{HF}$ for ICP-MS measurements (Upadhyay et al., 2009) and XRF (Okuda et al., 2013; Steinhoff et al., 2000; Itoh et al., 2018) analysis, the results from this method show lower detection limits for elements such as $\mathrm{Ca}, \mathrm{Zn}, \mathrm{Fe}$, and $\mathrm{Ti}$ but higher limits for Sr. For $\mathrm{Al}$ and $\mathrm{Co}$; the blank concentrations using the methods of this study were below the instrument detection limit. Comparatively to digestion procedures without HF, the application of HF (especially for analysis with ICPMS technique) leads to an increase in the blank for elements such as $\mathrm{Ca}, \mathrm{Ti}$, and $\mathrm{Fe}$, which are partly embedded into the filter matrix and readily dissolved by HF, yielding higher blanks for such elements as observed elsewhere (Upadhyay et al., 2009).

The differences between these studies may also be due to the use of different filter materials in these studies. However, the use of HF has often been associated with high blank values for quartz filters (Buck and Paytan, 2012; Cullen and Sherrell, 1999). This observation shows the advantages of applying TXRF for samples with low elemental concentrations using quartz filters especially as complete filter digestion is not required. However, for both this study and other reported studies, $\mathrm{Ca}, \mathrm{K}$, and $\mathrm{Zn}$ showed relatively higher blanks for 
Table 2. The average blank filter concentrations, method detection limit (MDL) of elements in both quartz (QF) and polycarbonate (PC) filter material $(\varnothing: 8 \mathrm{~mm}, n=3)$.

\begin{tabular}{|c|c|c|c|c|c|c|c|c|c|c|}
\hline \multirow[t]{2}{*}{ Quartz } & \multirow[t]{2}{*}{$\begin{array}{r}\text { Conc. } \\
\text { (ng) }\end{array}$} & \multirow[t]{2}{*}{$\begin{array}{l}\text { LLD } \\
(\mathrm{ng})\end{array}$} & \multicolumn{3}{|c|}{$\begin{array}{c}\mathrm{MDL} \\
\left(\mathrm{ng} \mathrm{cm}^{-2}\right)\end{array}$} & \multirow[t]{2}{*}{$\begin{array}{r}\text { Conc. } \\
\left(\operatorname{ng~g}^{-1}\right)^{\mathrm{c}}\end{array}$} & \multirow[t]{2}{*}{$\mathrm{PC}$} & \multirow[t]{2}{*}{$\begin{array}{r}\text { Conc. } \\
\text { (ng) }\end{array}$} & \multirow[t]{2}{*}{$\begin{array}{r}\text { LLD } \\
(\mathrm{ng})\end{array}$} & \multirow[t]{2}{*}{$\begin{array}{r}\mathrm{MDL} \\
\left(\mathrm{ng} \mathrm{cm}^{-2}\right)\end{array}$} \\
\hline & & & This study & $\mathrm{a}$ & $\mathrm{b}$ & & & & & \\
\hline $\mathrm{Ca}$ & 566 & 3.4 & 44.2 & 144 & 193 & 2243664 & $\mathrm{Ca}$ & 55.5 & 0.7 & 26.4 \\
\hline $\mathrm{Zn}$ & 172 & 0.3 & 6.3 & 24 & 16.2 & 1935 & $\mathrm{Zn}$ & 5.3 & 0.1 & 4.1 \\
\hline $\mathrm{K}$ & 132 & 3.4 & 35.1 & 40 & 82.2 & 297324 & $\mathrm{Fe}$ & 2.5 & 0.2 & 1.4 \\
\hline $\mathrm{Fe}$ & 25 & 0.4 & 1.3 & 80 & 67 & 52679 & $\mathrm{Ba}$ & 1.9 & 0.9 & 1.9 \\
\hline $\mathrm{Sb}$ & 5.0 & 3.6 & 1.8 & 102 & & 301 & $\mathrm{Cr}$ & 0.5 & 0.3 & 0.8 \\
\hline $\mathrm{Cr}$ & 4.9 & 0.7 & 1.2 & 68 & 13 & 2498 & $\mathrm{Sr}$ & 0.4 & 0.1 & 1.0 \\
\hline $\mathrm{Ba}$ & 4.3 & 0.7 & 10.7 & & & & $\mathrm{~K}$ & 0.4 & 0.1 & 0.5 \\
\hline $\mathrm{Ti}$ & 3.0 & 0.5 & 4.5 & 56 & 28.7 & 6169 & $\mathrm{Ti}$ & 0.3 & 0.1 & 0.7 \\
\hline $\mathrm{Cu}$ & 1.6 & 0.3 & 1.1 & 25 & 25.9 & 496 & $\mathrm{~V}$ & 0.3 & 0.3 & 0.6 \\
\hline $\mathrm{Pb}$ & 1.5 & 0.2 & 2.4 & 48 & 23.1 & 924 & $\mathrm{Ni}$ & 0.3 & 0.1 & 0.4 \\
\hline $\mathrm{Ni}$ & 1.4 & 0.4 & 1.0 & 28 & 6.9 & 1371 & $\mathrm{~Pb}$ & 0.2 & 0.1 & 0.4 \\
\hline V & 0.9 & 0.1 & 1.1 & 40 & 9.1 & 67 & $\mathrm{Cu}$ & 0.1 & 0.1 & 0.3 \\
\hline $\mathrm{Sr}$ & 0.7 & 0.2 & 1.1 & & & 1619 & $\mathrm{Rb}$ & 0.1 & 0.1 & 0.2 \\
\hline As & 0.7 & 0.1 & 0.8 & 24 & & 70 & As & 0.1 & 0.1 & 0.2 \\
\hline $\mathrm{Se}$ & 0.3 & 0.1 & 0.3 & 18 & 39.7 & 25 & $\mathrm{Se}$ & 0.1 & 0.04 & 0.1 \\
\hline Mn & 0.9 & 0.2 & 1.1 & 40 & 7.2 & 1674 & & & & \\
\hline
\end{tabular}

a Steinhoff et al. (2000). ${ }^{\mathrm{b}}$ Okunda et al. (2013). ${ }^{\mathrm{c}}$ Upadhyay et al. (2009).

quartz filters in comparison to the other elements. This suggests that quartz filters can be used in situations where higher concentrations of these elements, especially, Fe, K, Zn, and $\mathrm{Ca}$, are expected.

The effect of the baking of filters at higher temperatures revealed a decrease in the blank values. Three batches of filters were baked at $100^{\circ} \mathrm{C}$ for $24 \mathrm{~h}$, digested in reverse agua regia solution, and had $10 \mu \mathrm{L}$ aliquots analyzed for their blanks. As shown in Table 3, the blank values showed a decrease in concentrations for elements such as $\mathrm{Sb}, \mathrm{Ca}, \mathrm{V}, \mathrm{Sr}, \mathrm{Mn}, \mathrm{Zn}$, and $\mathrm{Ti}$ of more than $20 \%$. Elements such as $\mathrm{K}, \mathrm{Pb}, \mathrm{Ni}$, and Ba showed the lowest decrease of less than $5 \%$, while $\mathrm{Fe}, \mathrm{Cr}$, $\mathrm{As}$, and $\mathrm{Cu}$ showed no decrease, and Se showed an increase. This signifies that high-temperature baking is also a useful step in reducing the background concentrations of some elements in quartz fiber filters, especially when used in remote regions. Despite the lower blanks due to baking, the blank values of most of the elements were on average still higher than those in the polycarbonate filters, thereby, confirming the advantages of polycarbonate filters over quartz.

Table 4 summarizes the comparison between different acid digestion procedures on filter blank concentrations and the recovery of the elements on three field samples from the

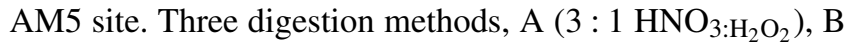
$\left(\mathrm{HNO}_{3}\right)$, and $\mathrm{C}\left(1: 3, \mathrm{HCl}: \mathrm{HNO}_{3}\right)$, were applied to these filters. Averagely, lower blank concentrations were observed using method $\mathrm{B}$, followed by $\mathrm{C}$ and $\mathrm{A}$. Using method $\mathrm{C}$, a higher recovery in comparison to the other methods (A and B) was observed. For most elements, the difference ranged between $5 \%$ and $60 \%$. This difference is likely related to
Table 3. Effect of temperature treatment on blank concentrations showing mean values (ng), standard deviation, and the ratio of the concentrations before and after pre-firing of filters $(n=3)$.

\begin{tabular}{lrr|rrr}
\hline \multirow{2}{*}{ Elements } & \multicolumn{2}{c|}{ Before } & \multicolumn{2}{|c}{ After } & Ratio \\
\cline { 2 - 4 } & Mean & SD & Mean & SD & Before/after \\
\hline $\mathrm{Ca}$ & 148 & 94 & 108 & 45 & 1.37 \\
$\mathrm{Zn}$ & 13 & 6.1 & 10 & 4.3 & 1.29 \\
$\mathrm{~K}$ & 5.7 & 0.8 & 5.4 & 0.8 & 1.05 \\
$\mathrm{Fe}$ & 3.5 & 3 & 3.5 & 1.2 & 1.01 \\
$\mathrm{Ni}$ & 1.4 & 1.8 & 1.3 & 0.1 & 1.02 \\
$\mathrm{Sb}$ & 1.3 & 1.1 & 0.9 & 0.6 & 1.52 \\
$\mathrm{Ba}$ & 0.9 & 0.7 & 0.9 & 0.2 & 1.02 \\
$\mathrm{Cr}$ & 0.9 & 0.9 & 0.9 & 0.9 & 1 \\
$\mathrm{Ti}$ & 0.3 & 0.1 & 0.2 & 0.1 & 1.21 \\
$\mathrm{Sr}$ & 0.2 & 0.1 & 0.1 & 0.1 & 1.36 \\
$\mathrm{Cu}$ & 0.13 & 0.05 & 0.13 & 0.09 & 0.98 \\
$\mathrm{~Pb}$ & 0.07 & 0.01 & 0.06 & 0.01 & 1.04 \\
$\mathrm{~V}$ & 0.04 & 0.02 & 0.03 & 0.03 & 1.37 \\
$\mathrm{As}$ & 0.04 & 0.01 & 0.04 & 0.01 & 1 \\
$\mathrm{Se}$ & 0.01 & 0 & 0.01 & 0 & 0.81 \\
$\mathrm{Mn}$ & 0.02 & 0.03 & 0.01 & 0 & 1.43 \\
\hline
\end{tabular}

the efficiency of the solution to clean the filter's surface effectively and get a homogeneous mixture of the particles in the solution. Similar to other studies (Zhao et al., 2015; Dehghani et al., 2018) we observe that although the inverse aqua regia solution does not provide the lowest blank values for the majority of the elements as nitric acid digestion, the re- 
covery of the elements under the digestion protocol is significantly higher. This indicates that reverse aqua regia solution is more suitable for the dissolution of quartz filters for TXRF measurements.

\subsubsection{Comparison of TXRF and ion chromatography data}

$\mathrm{Ca}$ and $\mathrm{K}$ were analyzed with both TXRF and ion chromatography (ICS3000, Thermo Fischer, USA). Particulate matter on quartz fiber filters was dissolved in high-purity deionized water through sonification and subsequent shaking for $1 \mathrm{~h}$ and the solution filtered through a $0.45 \mu \mathrm{m}$ syringe filter to get rid of colloidal particles that could eventually block the chromatographic columns. Aliquots of the filtrates were analyzed for the soluble $\mathrm{Ca}$ and $\mathrm{K}$ content using both techniques. Figure 4 shows a comparison between the obtained values from both instruments. Within a $95 \%$ confidence interval, good agreement was observed between the values from these instruments with an $r^{2}>0.86$. For both elements, slightly higher concentrations were observed with the IC with an average bias of about $7 \%$ in comparison to TXRF. As these are different measurement techniques with differences in detection and quantification procedures, one reason for this discrepancy could lie in the quantification uncertainties relating to the separation of neighboring peaks such as $\mathrm{Ca}(\mathrm{K}$ line: $3.692 \mathrm{keV}$ ) and $\mathrm{Sb}$ (L line: $3.604 \mathrm{keV}$ ) and in the evaluation of the background signals of both instruments. Differences of up to $8 \%$ were observed between IC and TXRF for $\mathrm{Cl}$ in nuclear fuel samples (Dhara et al., 2012). Despite such matrix specific differences, the regressions indicate satisfactory linearity between the two techniques and high compatibility of TXRF with other techniques when quantifying particulate matter elemental composition.

\subsubsection{Effect of plasma ashing}

Table 5 summarizes the effect of cold-plasma ashing of polycarbonate samples before and after treatment. For $\mathrm{Ca}, \mathrm{Sr}, \mathrm{Cr}$, $\mathrm{V}, \mathrm{Ni}, \mathrm{Pb}, \mathrm{Mn}$, and $\mathrm{Al}$ no significant difference was observed, while for $\mathrm{Fe}, \mathrm{K}, \mathrm{Ti}, \mathrm{Cu}, \mathrm{Rb}$, Mo differences of less than $5 \%$ were observed. As, $\mathrm{Se}, \mathrm{Ba}, \mathrm{Zn}$, and Co showed differences between $7 \%$ and $13 \%$, while the $\mathrm{Sb}$ difference was about $30 \%$. In general, the effect of plasma treatment was not significant for most of the elements for the samples collected at the CVAO. Hence, subsequent sample preparation of polycarbonate samples of size-resolved particulate matter samples was carried out without plasma treatment. This reduces analytical time and saves costs. It is, however, worth noting that although this procedure did not significantly increase trace metal concentrations for all the elements, for samples with high organic matter content this procedure can be useful to decrease background noise and improve the signal to noise ratio and analytical sensitivity. This is effective with biolog- ical samples (Woelfl et al., 2003) or when aerosol particles are directly collected on organic pastes (Prost et al., 2017).

\subsection{Field samples}

\subsubsection{Bulk aerosol samples}

Particulate matter $\mathrm{PM}_{10}$ samples collected at the AM5 station and measured with TXRF with the Mo-excitation anode were analyzed for their metal elements (Fig. 5). Figure 6 shows boxplots of the identified particulate matter trace metal concentrations at the AM5 station during August and early September 2017. The axis separates the elements according to their abundance, with elements of lower concentrations on the left in nanograms per cubic meter $\left(\mathrm{ng} \mathrm{m}^{-3}\right)$ and those with higher values on the right in micrograms per cubic meter $\left(\mu \mathrm{g} \mathrm{m}^{-3}\right)$. In detail, $\mathrm{Ca}$, was the most abundant element with a median concentration of $2.3 \mu \mathrm{g} \mathrm{m}^{-3}$, followed by $\mathrm{Al}$ $\left(1.1 \mu \mathrm{g} \mathrm{m}^{-3}\right), \mathrm{Fe}\left(1.0 \mu \mathrm{g} \mathrm{m}^{-3}\right)$, and $\mathrm{K}\left(0.5 \mu \mathrm{g} \mathrm{m}^{-3}\right)$. The least abundant elements were Co $\left(1.5 \mathrm{ng} \mathrm{m}^{-3}\right), \mathrm{Cu}\left(2.4 \mathrm{ng} \mathrm{m}^{-3}\right)$, $\mathrm{Ni}\left(3.2 \mathrm{ng} \mathrm{m}^{-3}\right)$, and $\mathrm{Pb}\left(4.4 \mathrm{ng} \mathrm{m}^{-3}\right)$. These values did not vary significantly between daytime and nighttime measurements (Table 6). Indeed, the variation in the elemental concentrations between daytime and nighttime samples was often less than $5 \%$ as illustrated in Table 6. Elements such as $\mathrm{Pb}, \mathrm{V}, \mathrm{Ni}$, and $\mathrm{Cu}$ showed an increase during the nighttime measurements in comparison to the daytime measurements. This indicates that these elements could have had a small nighttime source from the nearby cities due to the changing air mass inflow to the mountains at nighttime. $\mathrm{Ca}, \mathrm{Al}, \mathrm{Ti}, \mathrm{K}$, and $\mathrm{Fe}$ were higher during the daytime, which was coincidental as most dust events were stronger during daytime than nighttime. The elements showed in general strong variation during the investigated sampling period with a wide range of concentrations observed as revealed by their broad concentration ranges indicated by the edges of the whisker. In comparison to concentrations reported for different locations in Tunis, Tunisia (Kchih et al., 2015), the values in this study were similar for elements such as $\mathrm{K}, \mathrm{Cr}, \mathrm{Cu}, \mathrm{Mn}, \mathrm{Ni}, \mathrm{V}$, and $\mathrm{Zn}$. They observed higher values for $\mathrm{Ca}\left(<10 \mu \mathrm{g} \mathrm{m}^{-3}\right)$, and $\mathrm{Pb}\left(<2 \mu \mathrm{g} \mathrm{m}^{-3}\right)$ and lower values for $\mathrm{Fe}\left(<0.7 \mu \mathrm{g} \mathrm{m}^{-3}\right), \mathrm{Al}$ $\left(<0.6 \mu \mathrm{g} \mathrm{m}^{-3}\right)$, and $\mathrm{Ti}\left(0.08 \mu \mathrm{g} \mathrm{m}^{-3}\right)$. The AM5 station concentrations of most elements were higher than those observed at other regional background regions in southern Africa and Europe. For elements such as $\mathrm{Ca}, \mathrm{Al}, \mathrm{Fe}$, and $\mathrm{Zn}$, the concentrations in this study were higher than those reported for similar background regions in Welgegung, South Africa (Venter et al., 2017), and Puy-de-Dôme, France (Vlastelic et al., 2014). Venter et al. (2017) observed mean concentrations of $1.1 \mu \mathrm{g} \mathrm{m}^{-3} \mathrm{Ca}, 0.17 \mu \mathrm{g} \mathrm{m}^{-3} \mathrm{Al}, 1.2 \mu \mathrm{g} \mathrm{m}^{-3} \mathrm{Fe}$, and $0.05 \mu \mathrm{g} \mathrm{m}^{-3}$ for $\mathrm{Zn}$, while Vlastelic et al. (2014) observed, at the Puy-de-Dôme mountain site, mean concentrations of $115 \mathrm{ng} \mathrm{m}^{-3} \mathrm{Al}, 62 \mathrm{ng} \mathrm{m}^{-3} \mathrm{Fe}$, and $9.4 \mathrm{ng} \mathrm{m}^{-3} \mathrm{Zn}$. For elements such as $\mathrm{Ni}$ and $\mathrm{Cu}$, lower concentrations were observed at $\operatorname{AM} 5\left(4.4,3.0 \mathrm{ng} \mathrm{m}^{-3}\right)$, respectively, in compari- 
Table 4. Elemental concentrations (ng) of different digestion procedure on blank quartz filter and field samples from the AM5 site.

\begin{tabular}{|c|c|c|c|c|c|c|c|c|c|c|c|c|}
\hline \multirow[t]{3}{*}{ Elements } & \multicolumn{6}{|c|}{ Blank $(n=3)$} & \multicolumn{6}{|c|}{ Field samples $(n=3)$} \\
\hline & \multicolumn{2}{|c|}{ Method A } & \multicolumn{2}{|c|}{ Method B } & \multicolumn{2}{|c|}{ Method C } & \multicolumn{2}{|c|}{ Method A } & \multicolumn{2}{|c|}{ Method B } & \multicolumn{2}{|c|}{ Method C } \\
\hline & Mean & SD & Mean & SD & Mean & SD & Mean & SD & Mean & SD & Mean & SD \\
\hline $\mathrm{Al}$ & bdl & bdl & bdl & bdl & bdl & bdl & 183 & 45 & 117 & 25 & 273 & 78 \\
\hline $\mathrm{K}$ & 4.7 & 0.3 & 4.3 & 0.2 & 4.1 & 0.4 & 52 & 15 & 35 & 7 & 66 & 17 \\
\hline $\mathrm{Ca}$ & 32 & 3.3 & 31 & 2.3 & 28.3 & 2.7 & 146 & 34 & 138 & 29 & 159 & 56 \\
\hline $\mathrm{Ti}$ & 0.1 & 0.03 & 0.09 & 0.02 & 0.10 & 0.02 & 11 & 2.5 & 5.4 & 1.1 & 14.2 & 3.2 \\
\hline V & 0.04 & 0.01 & 0.04 & 0.01 & 0.03 & 0.01 & 0.3 & 0.1 & 0.2 & 0.03 & 0.4 & 0.1 \\
\hline $\mathrm{Cr}$ & 0.3 & 0.1 & 0.1 & 0.05 & 0.7 & 0.3 & 0.6 & 0.1 & 0.3 & 0.1 & 0.5 & 0.1 \\
\hline Mn & 0.03 & 0.02 & 0.01 & 0.01 & 0.04 & 0.03 & 2.2 & 0.2 & 1.9 & 0.1 & 2.8 & 0.3 \\
\hline $\mathrm{Fe}$ & 1.5 & 0.5 & 0.5 & 0.25 & 3.1 & 1.5 & 108 & 35 & 68 & 17 & 155 & 43 \\
\hline $\mathrm{Ni}$ & 0.2 & 0.09 & 0.04 & 0.01 & 0.2 & 0.1 & 0.4 & 0.10 & 0.1 & 0.05 & 0.2 & 0.1 \\
\hline $\mathrm{Cu}$ & 0.03 & 0.01 & 0.08 & 0.03 & 0.08 & 0.04 & 0.2 & 0.03 & 0.2 & 0.03 & 0.2 & 0.03 \\
\hline $\mathrm{Zn}$ & 2.4 & 0.2 & 2.5 & 0.2 & 2.0 & 0.12 & 2.2 & 0.3 & 2.4 & 0.2 & 2.6 & 0.3 \\
\hline As & 0.03 & 0.01 & 0.04 & 0.01 & 0.04 & 0.01 & 0.04 & 0.01 & 0.04 & 0.01 & 0.04 & 0.01 \\
\hline $\mathrm{Se}$ & 0.01 & 0.01 & 0.01 & 0.01 & 0.01 & 0.01 & 0.01 & 0.01 & 0.01 & 0.01 & 0.01 & 0.01 \\
\hline $\mathrm{Rb}$ & bdl & bdl & bdl & bdl & bdl & bdl & 0.2 & 0.1 & 0.1 & 0.1 & 0.3 & 0.1 \\
\hline $\mathrm{Sr}$ & 0.06 & 0.01 & 0.05 & 0.01 & 0.05 & 0.01 & 1.2 & 0.1 & 1.0 & 0.1 & 1.4 & 0.3 \\
\hline $\mathrm{Sb}$ & 0.5 & 0.2 & 0.3 & 0.2 & 0.6 & 0.3 & 2.8 & 0.4 & 2.4 & 0.1 & 2.5 & 0.3 \\
\hline $\mathrm{Ba}$ & bdl & bdl & 0.08 & 0.02 & 0.04 & 0.01 & 2.0 & 0.3 & 1.8 & 0.1 & 2.3 & 0.3 \\
\hline $\mathrm{Pb}$ & 0.09 & 0.02 & 0.80 & 0.20 & 0.04 & 0.01 & 0.5 & 0.1 & 0.5 & 0.1 & 0.6 & 0.2 \\
\hline
\end{tabular}
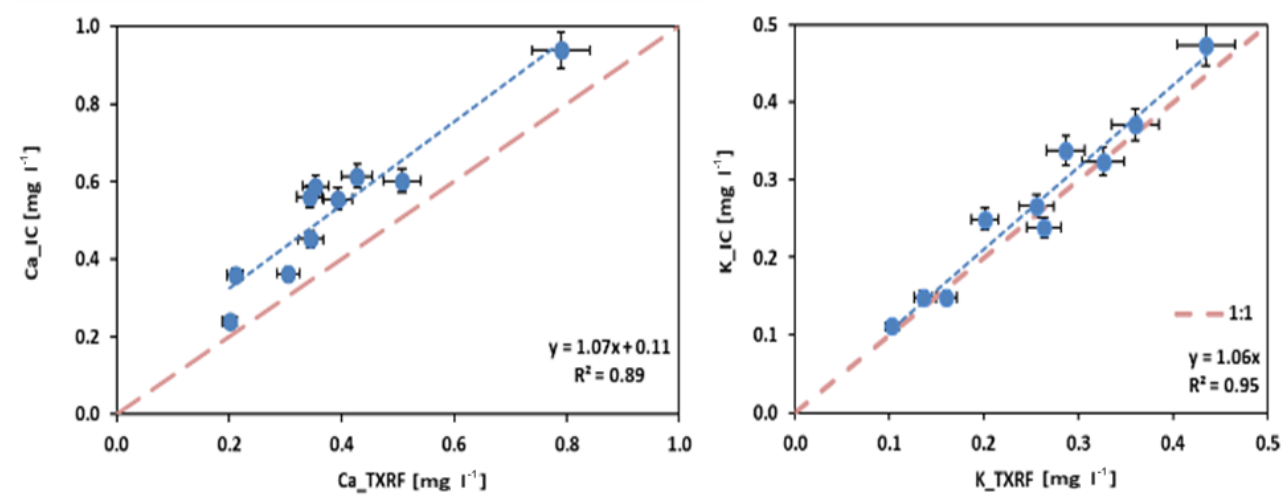

Figure 4. Comparison of $\mathrm{Ca}$ and $\mathrm{K}$ values of aerosol extracts in water measured by TXRF and ion chromatography ICS 3000.

son to Welgegung (7.9, 6.9 $\left.\mathrm{ng} \mathrm{m}^{-3}\right)$ and Puy-de-Dôme (1.9, $\left.5.8 \mathrm{ng} \mathrm{m}^{-3}\right)$. Sb concentration in this study was higher than at Welgegung and Puy-de-Dôme sites but lower than those observed at other urban sites (Cheng et al., 2000). This could be partly due to the interference of the Sb signal with the high Ca signal in the samples as well as the different sources in the respective regions. The higher values observed in this study are mainly due to the influence of Saharan dust during the sampling period. The particulate matter mass concentration during the sampling period was up to $145 \mu \mathrm{g} \mathrm{m}{ }^{-3}$. Based on the reddish-brown color of the filters, the predominant southwest winds, and back-trajectory information, these high concentrations were indicative of a strong influence of Saharan dust. However, the values of this study are within reported range for mineral dust dominated particulate matter (Cardoso et al., 2018; Patey et al., 2015).

The temporal variation in some elements during the investigated period is depicted in Fig. 7. Strong concentration fluctuations were observed for the elements as shown in Fig. 7 for $\mathrm{Ca}, \mathrm{Al}, \mathrm{Fe}, \mathrm{K}$, and $\mathrm{Ti}$. The highest concentrations of $\mathrm{Ca}, \mathrm{Al}$, and Fe were observed on 12 and 13 August 2017, while the lowest concentrations were observed on 17 and 21 August 2017. For other elements such as $\mathrm{Cu}, \mathrm{Zn}$, and $\mathrm{Sb}$, the 12 and 13 August 2017 were the days with the highest concentrations, while 21 June 2017 and 26 August 2017 were the days with the lowest concentrations. Air-mass trajectory investigations indicated that on 12 and 13 August 2017, an air mass from the Saharan desert passing through urban cities arrived 
Table 5. Effect of cold-plasma treatment on samples collected on polycarbonate filters. The mean values and the standard deviation from the mean are shown. Values are given in $\mathrm{ng}(n=5)$.

\begin{tabular}{lrr|rrr}
\hline \multirow{2}{*}{ Elements } & \multicolumn{2}{c|}{ Before } & \multicolumn{2}{c}{ After } & \multirow{2}{*}{ Ratio } \\
\cline { 2 - 4 } & Mean & SD & Mean & SD & After/before \\
\hline $\mathrm{Al}$ & 4671 & 475 & 4733 & 581 & 1.01 \\
$\mathrm{As}$ & 0.7 & 0.3 & 0.8 & 0.3 & 1.06 \\
$\mathrm{Ba}$ & 57 & 7.5 & 61 & 3.9 & 1.07 \\
$\mathrm{Ca}$ & 5325 & 250 & 5340 & 273 & 1.00 \\
$\mathrm{Co}$ & 1.01 & 1.6 & 1.14 & 1.3 & 1.13 \\
$\mathrm{Cr}$ & 15 & 0.9 & 15 & 1.5 & 1.00 \\
$\mathrm{Cu}$ & 4.7 & 0.1 & 4.9 & 0.6 & 1.04 \\
$\mathrm{Fe}$ & 3460 & 275 & 3544 & 374 & 1.02 \\
$\mathrm{~K}$ & 2013 & 164 & 2058 & 202 & 1.02 \\
$\mathrm{Mn}$ & 65 & 2.5 & 64 & 2.8 & 0.98 \\
$\mathrm{Mo}$ & 25 & 7.9 & 26 & 14 & 1.04 \\
$\mathrm{Ni}$ & 6.6 & 0.5 & 6.6 & 0.5 & 1.00 \\
$\mathrm{~Pb}$ & 3.6 & 0.4 & 3.6 & 0.7 & 1.00 \\
$\mathrm{Rb}$ & 7.7 & 0.2 & 7.9 & 1.1 & 1.03 \\
$\mathrm{Sb}$ & 35 & 28 & 47 & 5.7 & 1.34 \\
$\mathrm{Se}$ & 0.6 & 0.04 & 0.7 & 0.05 & 1.07 \\
$\mathrm{Sr}$ & 59 & 3 & 59 & 2.6 & 1.00 \\
$\mathrm{Ti}$ & 308 & 27 & 315 & 41 & 1.02 \\
$\mathrm{~V}$ & 8.5 & 0.8 & 8.5 & 1 & 1.00 \\
$\mathrm{Zn}$ & 7.4 & 0.6 & 8.2 & 0.8 & 1.11 \\
& & & & & \\
& & & &
\end{tabular}

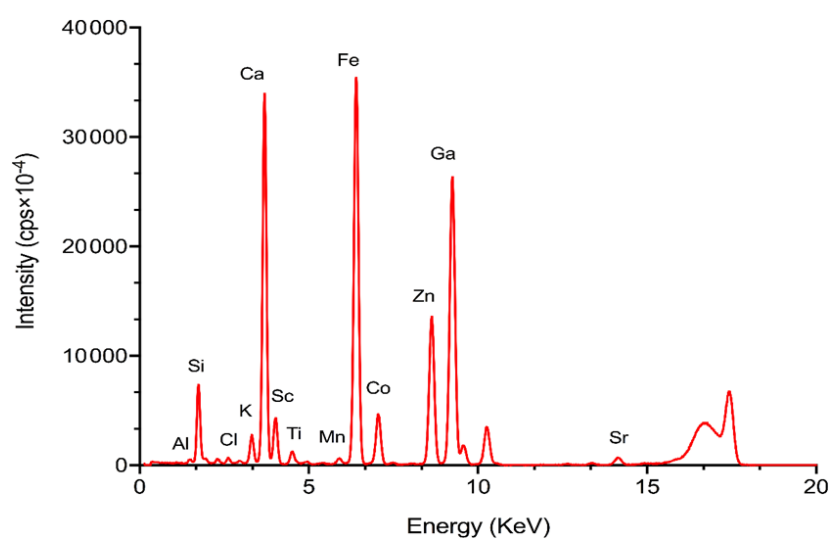

Figure 5. TXRF spectra of particulate matter $\mathrm{PM}_{10}$ samples collected at the AM5 station and measured with the Mo-excitation anode for their metal element.

at the AM5 site, while on 21 and 26 August 2017 the air masses mainly crossed over the cities without passing over the Sahara. These differences indicated the strong variation observed in the air mass inflow at the remote mountainous site. Elements such as $\mathrm{Al}, \mathrm{Ti}$, and Fe showed a similar temporal variation in their concentrations especially during the period of intense dust influence, while Ca variation was different after the dust event, indicating other sources influence its concentration. The similarity amongst the other elements

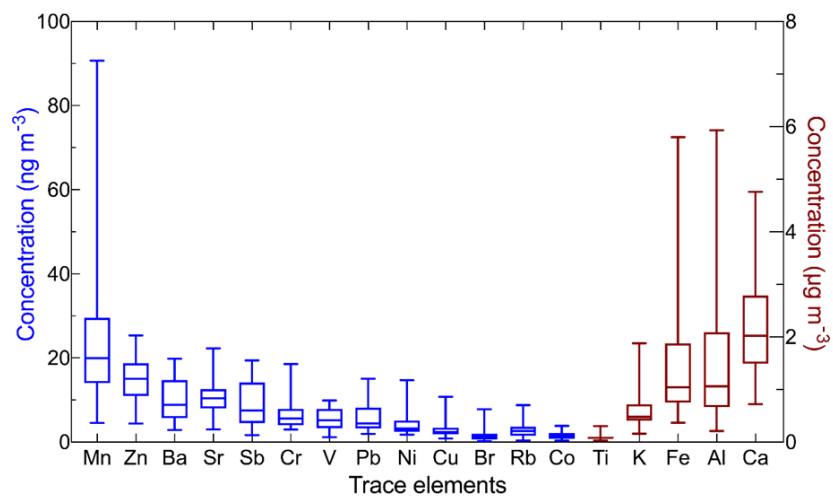

Figure 6. Boxplots of ambient aerosol trace metal concentrations observed at the AM5 station during August and early September 2017.

Table 6. Daytime and nighttime elemental concentrations at the AM5 station.

\begin{tabular}{lrr|rr}
\hline \multirow{2}{*}{ Elements } & \multicolumn{2}{c|}{ Day } & \multicolumn{2}{c}{ Night } \\
\cline { 2 - 5 } & Mean & SD & Mean & SD \\
\hline $\mathrm{Ca}$ & 2301.0 & 1028.2 & 2201.0 & 928.2 \\
$\mathrm{Al}$ & 1663.0 & 1449.0 & 1563.0 & 1349.0 \\
$\mathrm{Fe}$ & 1539.0 & 1256.0 & 1439.0 & 1156.0 \\
$\mathrm{~K}$ & 655.0 & 437.4 & 555.0 & 337.4 \\
$\mathrm{Ti}$ & 110.4 & 116.0 & 90.4 & 16.0 \\
$\mathrm{Mn}$ & 25.2 & 18.8 & 25.1 & 18.7 \\
$\mathrm{Zn}$ & 15.1 & 5.4 & 15.0 & 5.3 \\
$\mathrm{Sr}$ & 10.6 & 3.9 & 10.5 & 3.8 \\
$\mathrm{Ba}$ & 10.4 & 5.1 & 10.3 & 5.0 \\
$\mathrm{Sb}$ & 9.2 & 5.5 & 9.1 & 5.4 \\
$\mathrm{Ru}$ & 8.8 & 4.0 & 8.7 & 3.9 \\
$\mathrm{Cr}$ & 6.9 & 4.0 & 6.8 & 3.9 \\
$\mathrm{~Pb}$ & 5.9 & 3.7 & 6.1 & 3.6 \\
$\mathrm{~V}$ & 5.2 & 2.7 & 6.1 & 2.6 \\
$\mathrm{Ni}$ & 4.3 & 3.0 & 4.5 & 2.9 \\
$\mathrm{Rb}$ & 3.2 & 2.3 & 3.1 & 2.2 \\
$\mathrm{Cu}$ & 2.8 & 2.1 & 3.2 & 2.0 \\
$\mathrm{Br}$ & 1.7 & 1.6 & 1.6 & 1.5 \\
$\mathrm{Co}$ & 1.7 & 1.0 & 1.6 & 0.9 \\
\hline
\end{tabular}

is indicative of their similar origins either relating to their emission sources or their air mass inflow characteristics.

Typically, $\mathrm{Ca}, \mathrm{Al}, \mathrm{Ti}$, and $\mathrm{Fe}$ are elements associated with high crustal abundance, which will indicate a strong crustal matter influence at the AM5 site during the investigated period. $\mathrm{Cu}, \mathrm{Zn}$, and $\mathrm{Sb}$ are elements typical of traffic, industrial emissions, and waste incineration (Zhu et al., 2019).

\subsubsection{Size resolved aerosol measurements}

Table 7 shows the size-resolved elemental concentrations of aerosol particles observed at the CVAO during 2 weeks of measurements in January 2017. The concentration of each 


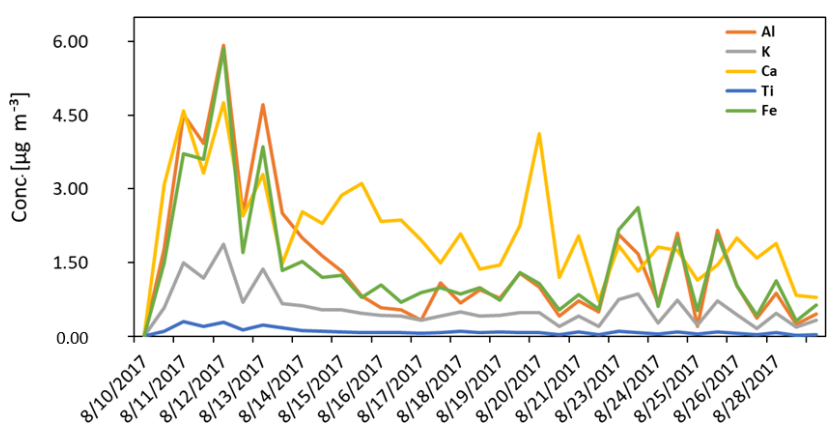

Figure 7. Temporal variation in elements observed at the AM5 station during the measurement period.

size fraction including the minimum, maximum, mean, and standard deviation of the elements as well as their total $\mathrm{PM}_{10}$ concentrations are presented. Al was the most abundant element in the $\mathrm{PM}_{10}$ particles with a mean concentration of $0.94 \mu \mathrm{g} \mathrm{m}^{-3}$, followed by $\mathrm{Fe}\left(0.82 \mu \mathrm{g} \mathrm{m}^{-3}\right)$ and $\mathrm{Ca}\left(0.60 \mu \mathrm{g} \mathrm{m}^{-3}\right)$. Cr $\left(1.4 \mathrm{ng} \mathrm{m}^{-3}\right)$, Co $\left(0.8 \mathrm{ng} \mathrm{m}^{-3}\right), \mathrm{Cu}$ $\left(0.6 \mathrm{ng} \mathrm{m}^{-3}\right)$, and $\mathrm{Se}\left(0.6 \mathrm{ng} \mathrm{m}^{-3}\right)$ were the least abundant elements. The difference between the least and the most abundant elements was over 3 orders of magnitude, indicating a strong variation in source regions and inter-daily meteorological influence on the ambient aerosol particle load at the CVAO during the investigated period.

The observed concentrations were found to be within the range of concentrations previously observed in this region, especially for $\mathrm{PM}_{10}$ elemental concentrations. Cardoso et al. (2018) observed yearly average $\mathrm{Fe}$ and $\mathrm{Ca}$ concentrations of 1.8 and $1.4 \mu \mathrm{g} \mathrm{m}^{-3}$ in Praia, Carbo Verde, while Patey et al. (2015) observed yearly mean Al concentrations of $0.76 \mu \mathrm{g} \mathrm{m}^{-3}$ at the CVAO. The differences observed between the present study and the literature values are based on the different measurement periods, yearly in comparison to the 2 weeks measurement, and the different seasons of measurement, especially as seasonal trends can markedly affect particulate matter concentrations. However, for the least abundant elements, their concentration ranges were higher than those reported for remote marine conditions at the CVAO. This indicates that during the investigated period, long-range transported air masses significantly influenced the particulate matter elemental composition. In comparison to other continental measurements, the values were similar to those observed in Wien (Austria) for $\mathrm{Ca}\left(<231 \mathrm{ng} \mathrm{m}^{-3}\right), \mathrm{Cu}(<$ $3.7 \mathrm{ng} \mathrm{m}^{-3}$ ), and $\mathrm{Ni}\left(<1.6 \mathrm{ng} \mathrm{m}^{-3}\right)$ (Prost et al., 2017).

Generally, AM5 elemental concentrations were higher than those observed at the CVA despite the indications that long-range transport of continental air masses influenced the ambient aerosol composition during the period of investigation at the CVAO. The differences observed at these stations are related to the differences in their location and, hence, their different exposure to air masses of varying origins. While the CVAO is a coastal remote site, constantly influ-

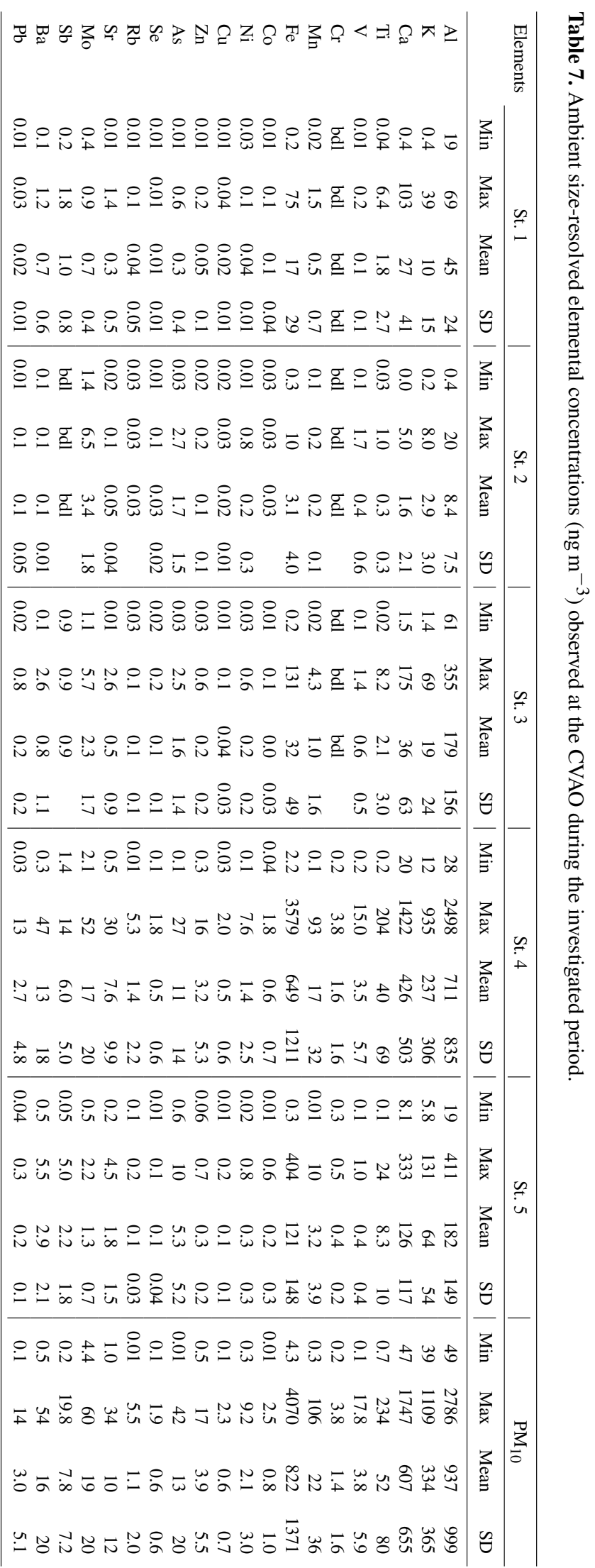




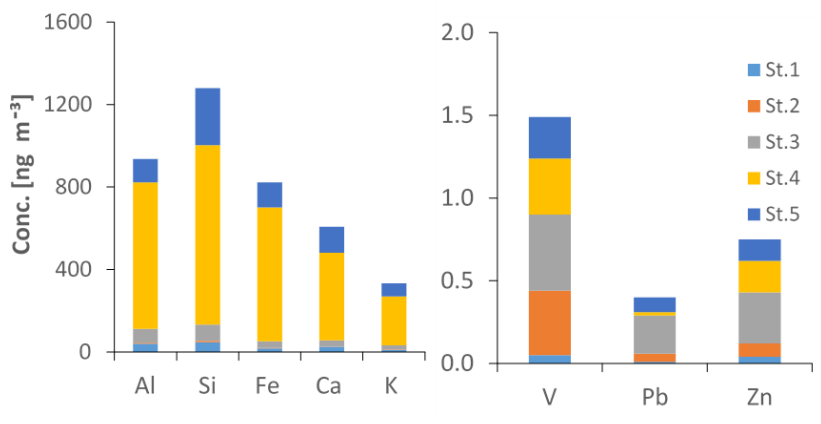

Figure 8. Size distribution of given elements with $\mathrm{Fe}, \mathrm{Ca}, \mathrm{K}$, and $\mathrm{Al}$ found in larger particles, while $\mathrm{V}, \mathrm{Pb}$, and $\mathrm{Zn}$ are found in smaller particles.

enced by oceanic and ship emissions, the AM5 station is a mountainous site, influenced strongly by crustal matter resuspension from the neighboring agricultural fields and the Saharan desert. As such, the variability in the elemental concentrations in these regions depends on the prevailing winds at the period of sampling as well as the local meteorological conditions. This could explain the differences in the concentrations observed at these two sites despite the influence of mineral dust in their elemental compositions.

Figure 8 shows an overview of the size distribution of given elements observed at the CVAO during the sampling period. $\mathrm{Ca}, \mathrm{Fe}, \mathrm{Al}, \mathrm{Si}, \mathrm{Ti}, \mathrm{Mn}, \mathrm{Rb}$, and $\mathrm{Sr}$ were more abundant in the coarse-mode particles (i.e., St. 3 to St. 5), while elements such as $\mathrm{Ni}, \mathrm{Pb}, \mathrm{V}, \mathrm{Pb}$, and $\mathrm{Zn}$ were more abundant in the fine-mode particles (i.e., St. 1 to St. 3). These differences in the size distribution indicate their different emission sources and likely different transport patterns.

\subsubsection{Method evaluation and limitations}

The presented methods for extracting PM from polycarbonate and quartz fiber filters show satisfactory reproducibility on reference materials; however, for quartz fiber filters it is difficult to establish the recovery of the particles on every aerosol type. Our experience shows that using the reverse aqua regia solution for digestion and washing off of urban particulate matter from the quartz surface, a clean filter is observed with very negligible particulate matter remaining on the filter. Similar observations were made also for filters that were dominated by mineral dust particulate matter mixed with soot particles. However, for field samples that have different properties from the SRM samples, the recovery of the elements via this method is difficult to estimate as the adhesion of the particles to the surface may differ. We, however, recommend that for such samples, a series of tests be done to establish typical recoveries of the required elements to improve their quantification in the given matrix. As observed in Table 2, the MDL with the digestion method is low for most elements in the blank filters except for $\mathrm{Ca}$ and $\mathrm{Zn}$ in the polycarbonate membrane and $\mathrm{Ca}, \mathrm{Zn}$, and $\mathrm{K}$ for the quartz fiber filters. Thus, if this method has to be applied to particulate matter elemental analysis, the expected concentrations should be higher for the given elements. Typically, polycarbonate and Teflon filters are more suitable for trace metal analysis as they could be digested without risk of high blank values. Nevertheless, as mentioned above, the utilization of quartz fiber filters has its merits as it reduces sampling cost and monitoring cost especially if the metals of interest are within concentration ranges that are far higher than the filter blanks. A general limitation of the PICOFOX instrument with the single Mo anode is that heavy metals (with $\mathrm{Z}>43$ ) can only be determined through their L lines, which leads to overlapping of their signals with the $\mathrm{K}$ lines of the lighter elements. This leads to higher uncertainties in the quantification of such elements especially when the element overlaps with other main matrix elements with high concentrations and broad peaks such as $\mathrm{Cl}, \mathrm{Ca}, \mathrm{K}, \mathrm{Ti}$, and $\mathrm{S}$ in mineral dust samples. This is the case for elements such as $\mathrm{Ru}$, $\mathrm{Sb}, \mathrm{Sn}, \mathrm{Ba}$, and Mo as observed with the recoveries of the CPA standards after filter digestion. When analyzing particulate matter samples from marine origin with high $\mathrm{Cl}$ and $\mathrm{Ca}$ concentrations, care must be taken in the quantification of $\mathrm{Ru}$ and $\mathrm{Sb}$. It is worth diluting the samples to evaluate the presence of these elements, especially as the deconvolution procedure may falsely attribute residual $\mathrm{Cl}$ or $\mathrm{Ca}$ signals to these elements due to their closeness. If the dilution does not lead to a proportionate signal, it is an indication of quantification error from the signal processing software. Despite these limitations, for investigations with limited sample material, as is the case with particulate matter samples, TXRF is quite sensitive and suitable for such analysis. As shown with the elemental content of size-resolved aerosol samples with particle sizes $<140 \mathrm{~nm}$, as well as those between 140$420 \mathrm{~nm}$, the analytical errors that can be encountered using filter digestion methods for such a small microgram sample mass are typically too high in comparison to those obtained with TXRF direct measurement method. This indeed illustrates the merit of this technique for ambient elemental particulate matter analysis.

\subsubsection{Cloud water samples}

The results of the determined elemental concentrations in five cloud water samples collected at the AM5 station during discrete cloud events are summarized in Table 8. Similar to the aerosol particle concentrations observed above, $\mathrm{Ca}(379 \mu \mathrm{g} \mathrm{L}-1)$ and $\mathrm{K}\left(331 \mu \mathrm{gL}^{-1}\right)$ were the most abundant elements, followed by $\mathrm{Zn}\left(17 \mu \mathrm{LL}^{-1}\right)$, Ba $(15 \mu \mathrm{g} \mathrm{L}-1)$, and $\mathrm{Fe}\left(5.1 \mu \mathrm{gL}^{-1}\right)$. Rb $\left(0.4 \mu \mathrm{gL}^{-1}\right), \mathrm{Cr}\left(0.3 \mu \mathrm{g} \mathrm{L}^{-1}\right)$, Se $\left(0.2 \mu \mathrm{g} \mathrm{L}^{-1}\right)$, and $\mathrm{Pb}\left(0.1 \mu \mathrm{g} \mathrm{L}^{-1}\right)$ were the least abundant elements. The observed concentrations and ranges of these elements are comparable to those reported for cloud water elsewhere. Bianco et al. (2017) reported similar concentration ranges for $\mathrm{Zn}(3.32-130 \mu \mathrm{gL}-1)$, Ti $\left(<12.89 \mu \mathrm{gL}^{-1}\right), \mathrm{Fe}$ 
$\left(<54.9 \mu \mathrm{gL}^{-1}\right)$, As $\left(<0.42 \mu \mathrm{g} \mathrm{L}{ }^{-1}\right), \mathrm{Sb}\left(0.02-0.42 \mu \mathrm{g} \mathrm{L}{ }^{-1}\right)$, and $\mathrm{Cu}\left(<55 \mu \mathrm{gL}^{-1}\right)$ in cloud water samples collected over a contracted period of 2 years at the Puy-de-Dôme in France. Despite the higher number of samples that encompassed different cloud origin and formation processes in their study in comparison to the samples in this study, the similarity in the concentration range is significant. In comparison to cloud water concentrations observed in the Thuringia forest at the Schmücke in Germany, the values of this study were generally lower, except for $\mathrm{V}$ whose concentration was higher (mean $0.8 \mu \mathrm{gL}^{-1}$; Thuringia forest $0.7 \mu \mathrm{gL}^{-1}$ ) in comparison to values observed at the Thuringia forest (Fomba et al., 2015). Similarly, the concentrations were lower than those observed at Mount (Mt.) Elden in Arizona (Hutchings et al., 2009). Despite the differences in the mean concentrations, the reported concentrations of this study are within the range of concentrations observed in other regions in $\mathrm{Eu}-$ rope and the USA. The differences in the absolute values are related to the different sample collection locations. In comparison to measurements performed in regions in China, the trace metal concentrations in this study were significantly lower. Liu et al. (2012), reported concentrations of $\mathrm{Zn}$ $\left(249.1 \mu \mathrm{gL}^{-1}\right), \mathrm{Mn}\left(42.84 \mu \mathrm{gL}^{-1}\right), \mathrm{Fe}\left(108.8 \mu \mathrm{gL}^{-1}\right)$, and $\mathrm{Pb}\left(46.2 \mu \mathrm{g} \mathrm{L}^{-1}\right)$ at Mt. Tai, which is more than an order of magnitude higher than those at the Atlas mountain site. Similar high concentrations were also reported at Mt. Heng (Li et al., 2017), $\mathrm{Zn}\left(224.6 \mu \mathrm{g} \mathrm{L}{ }^{-1}\right), \mathrm{Pb}(100.5 \mu \mathrm{L})$, and As $\left(19.9 \mu \mathrm{gL}^{-1}\right)$, and at Mt. Lu (Li et al., 2013), Zn $\left(200 \mu \mathrm{gL}^{\mathrm{L}}\right)$, $\mathrm{Fe}\left(88 \mu \mathrm{g} \mathrm{L}^{-1}\right)$, and $\mathrm{Pb}\left(77 \mu \mathrm{gL}^{-1}\right)$, in China. This indicates a strong contrast in the trace metal levels in cloud water in northern African mountain regions as compared to more polluted regions in China.

\subsection{Crustal matter contribution to element abundance}

Enrichment factor (EF) analysis was performed to evaluate the contribution of crustal matter to the trace metal levels. Ti was used as the reference element for crustal matter as it had a higher recovery than $\mathrm{Al}$, and it has been used in many studies as a reference element since its anthropogenic sources are few (Shelley et al., 2015; Buck et al., 2019). The EF for an element $\mathrm{Z}$ is defined as $(\mathrm{Z} / \mathrm{Ti})$ aerosol/ $(\mathrm{Z} / \mathrm{Ti})$ soil. For the soil reference concentrations, the average upper-continental crust values (Wedepohl, 1995) were used.

Figure 9 shows the average enrichment factors for the elements at the AM5 and the CVAO sites. From both stations, $\mathrm{Al}, \mathrm{Fe}, \mathrm{Mn}, \mathrm{Ca}, \mathrm{K}, \mathrm{Sr}, \mathrm{Ba}$, and $\mathrm{Rb}$ were dominated from crustal sources. Their EF were within those of the reference upper-continental crust values. Sb, As, Mo, and Se showed high enrichment especially at the CVAO site in both the fineand coarse-mode fraction. This indicates their non-crustal and probable anthropogenic sources. Mo and Se are emitted from oceanic emissions as well as coal combustion (Cho and Wu, 2004; Weller et al., 2008), while Sb is often used as a brake lubricant and hence often emitted from traffic activities
(Pant and Harrison, 2013; He et al., 2012). These elements are also sourced from coal combustion (Pan et al., 2013; Tian et al., 2014). The other elements showed low enrichment, indicating a combination of crustal and anthropogenic sources contributing to their emissions. These elements included Ni, $\mathrm{V}, \mathrm{Co}, \mathrm{Cr}, \mathrm{Cu}, \mathrm{Zn}$, and $\mathrm{Pb}$.

Using Pearson's correlation analysis, groups of elements could be identified. $\mathrm{Fe}, \mathrm{Mn}, \mathrm{Ti}, \mathrm{K}$, and $\mathrm{Al}$ showed good correlation amongst each other with $r>0.91$ within a $95 \%$ confidence interval, confirming that these elements were mostly of crustal origin. $\mathrm{Ca}, \mathrm{Cu}, \mathrm{Cr}, \mathrm{Ni}, \mathrm{V}$, and $\mathrm{Pb}$ also revealed satisfactory correlation amongst themselves, although it was weaker in comparison to the crustal metal groups with $r>$ 0.7 within a $90 \%$ confidence interval. This group of elements is indicative of the presence of road and urban dust, originating from resuspension of nearby roadside particles containing non-exhaust and exhaust car emissions (Milando et al., 2016) or dust from construction sites, which are common in the nearby cities close to the AM5 sites. Pb, V, and $\mathrm{Ni}$ are often emitted from fuel and oil combustion (Pacyna et al., 2007), while $\mathrm{Zn}, \mathrm{Cr}$, and $\mathrm{Cu}$ are emitted from traffic activities relating to tire and brake wear, as well as metallurgical industries and waste incineration (Font et al., 2015; Harrison et al., 2012). As these sites are located in remote regions, far away from local contamination, trace metals at these sites are as a result of long-range transport from the continent over the oceans to the CVAO or from neighboring cities to the Atlas mountain.

\section{Conclusion}

TXRF has been investigated for its appropriateness in determining trace metal concentrations in particulate matter sampled on quartz and polycarbonate substrates as well as on cloud water samples. Methods for determining the elemental concentrations in these matrices were developed and tested on commercial standard reference material. The test results showed good agreement between determined values and commercially certified values obtained from different techniques. Extraction procedures for the preparation of particulate matter collected on membranes and quartz fiber filters using microwave digestion were assessed, and the evaluated concentrations from this method were compared with those obtained from direct measurements without sample digestion procedure. The results showed good agreement between the results obtained from both methods. It was observed that the pre-firing of quartz filters reduces the blank concentrations of some elements and that reverse aqua regia digestion provided comparatively lower blanks but higher recovery when applied to field samples. This indicated its effectiveness in cleaning aerosol particles from quartz filter surfaces. Despite its high sensitivity, care should be taken when performing aerosol multielement analysis with TXRF as overlapping of signals between $\mathrm{K}$ lines of light elements 
Table 8. Trace metal concentrations $\left(\mu \mathrm{gL}^{-1}\right)$ in cloud water samples in the Atlas mountain region collected at the AM5 station and those observed in other regions in Asia and Europe.

\begin{tabular}{|c|c|c|c|c|c|c|c|c|c|c|c|}
\hline \multirow{2}{*}{$\begin{array}{l}\text { Elements } \\
\mu \mathrm{gL}^{-1}\end{array}$} & \multicolumn{2}{|c|}{ Atlas station $^{\mathrm{a}}$} & \multicolumn{2}{|c|}{ Mt. Heng ${ }^{b}$} & \multicolumn{2}{|c|}{ Mt. Tai ${ }^{\mathrm{c}}$} & \multicolumn{2}{|c|}{ Puy-de-Dôme ${ }^{\mathrm{d}}$} & \multicolumn{2}{|c|}{ Schmücke ${ }^{\mathrm{e}}$} & \multirow{2}{*}{$\begin{array}{r}\text { Mt. Elden }{ }^{\mathrm{f}} \\
\text { Mean }\end{array}$} \\
\hline & Range & Mean & Range & Mean & Range & Mean & Range & Mean & Range & Mean & \\
\hline $\mathrm{Ca}$ & $<682$ & 379 & & & & & & & & & \\
\hline $\mathrm{K}$ & $144-645$ & 331 & & & & & & & & & \\
\hline $\mathrm{Zn}$ & $<42$ & 17 & $0.1-3257$ & 224.6 & $8.6-2775$ & 249.1 & $3.3-130.4$ & 57.5 & & & \\
\hline $\mathrm{Ba}$ & $8-25$ & 15 & $0.01-138$ & 12.7 & & & & & & & 15.2 \\
\hline $\mathrm{Fe}$ & $<22$ & 5.1 & $12.3-876$ & 155.2 & $<1369$ & 105.8 & $<54.93$ & 4.5 & & & 5.6 \\
\hline $\mathrm{Ni}$ & $1.9-13$ & 6.3 & $0.46-81.7$ & 7.2 & $<142.2$ & 9.3 & & & & & 5.7 \\
\hline $\mathrm{Mn}$ & $2.2-8.9$ & 4.4 & $0.49-694$ & 34.0 & $0.6-1645$ & 42.8 & $<9.1$ & 1.1 & $0.1-30.1$ & 5.59 & 34 \\
\hline $\mathrm{Sr}$ & $0.1-5.8$ & 1.9 & & & & & $0.3-6.2$ & 1.6 & $0.2-13.5$ & 2.45 & \\
\hline $\mathrm{Cu}$ & $0.8-5.6$ & 2.5 & $0.01-424$ & 11.7 & $<113.8$ & 9.2 & $<55.7$ & 10.2 & & & 25 \\
\hline $\mathrm{Sb}$ & $<4.8$ & 1 & $0.01-31.8$ & 2.6 & & & $<0.42$ & 0.1 & & & \\
\hline $\mathrm{Ti}$ & $<4.6$ & 1.5 & & & & & $<12.9$ & 2.9 & $0.1-79.1$ & 9.18 & \\
\hline V & $<2.1$ & 0.8 & $0.16-29.2$ & 2.3 & & & $0.04-3.9$ & 0.8 & $0.1-2.5$ & 0.71 & 3.2 \\
\hline $\mathrm{Cr}$ & $<0.8$ & 0.3 & $0.01-14.3$ & 1.6 & $<11.53$ & 0.9 & & & $0.3-52$ & 5.54 & 1.7 \\
\hline $\mathrm{Rb}$ & $<0.5$ & 0.4 & & & & & $<1.1$ & 0.4 & $0.1-1.7$ & 0.57 & \\
\hline $\mathrm{Pb}$ & $<0.3$ & 0.1 & $0.01-1421$ & 100.5 & $<619.5$ & 46.2 & $<2.6$ & 0.3 & $0.3-10.5$ & 1.4 & 0.4 \\
\hline $\mathrm{Se}$ & $<0.3$ & 0.2 & $0.56-58.3$ & 5.7 & & & & & $0.1-4.9$ & 1.38 & 2 \\
\hline
\end{tabular}

${ }^{a}$ This study. ${ }^{\mathrm{b}}$ Li et al. (2017). ${ }^{\mathrm{c}}$ Liu et al. (2012). ${ }^{\mathrm{d}}$ Bianco et al. (2017). ${ }^{\mathrm{e}}$ Fomba et al. (2015). ${ }^{\mathrm{f}}$ Hutchings et al. (2009).
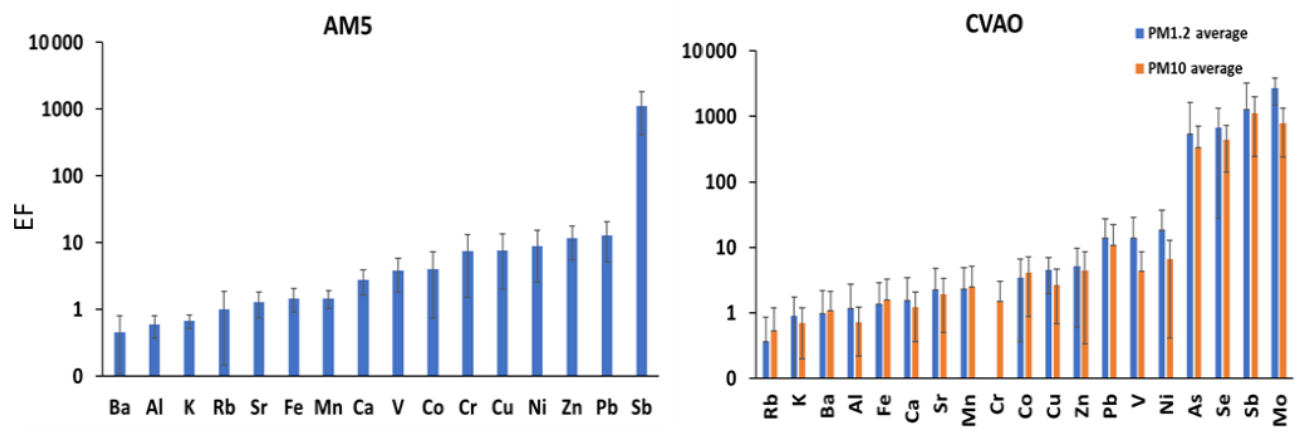

Figure 9. Crustal enrichment factors of samples collected at the AM5 station and the CVAO sorted in ascending order of the enrichment of the observed elements.

and $\mathrm{L}$ lines of heavier elements may lead to faulty conclusions. The methods were applied successfully to field samples of particulate matter and cloud water collected at different regions in Morocco and Cabo Verde. The determined elemental concentrations obtained from these samples (both size-resolved and bulk particulate matter) and cloud water samples were similar to those reported elsewhere. The determined trace metals such as $\mathrm{Fe}, \mathrm{Ca}, \mathrm{Al}, \mathrm{Ti}$, and $\mathrm{Mn}$ showed strong correlation amongst themselves indicating their common crustal origin. The results indicate that TXRF is a useful and complementary tool for determining elemental concentrations in the fine and coarse particulate matter as well as in cloud water.
Data availability. All data will be made available upon request by the authors.

Author contributions. AM, HH, RCEM, MH, and SEH designed the experiment at the AM5 station, and IO and EME collected the samples at the AM5 site. SEIB, performed the TXRF measurements for the particles, and ND carried out the cloud water and bulk aerosol sampling at the AM5 site, performed the TXRF investigations and analysis, and assembled the data. $\mathrm{HH}$ and KWF designed the experiment at the CVAO. KWF compiled the analysis and prepared the article. All authors reviewed and edited the article and contributed to the discussion.

Competing interests. The authors declare that they have no conflict of interest. 
Acknowledgements. The authors would like to thank Luis Neves for assistance in sample collection at the CVAO. The authors would also acknowledge the support of Mrs. Julia Wilk and Cornelia Pielok for their support with the trace metal analysis.

Financial support. This research has been supported by the European Union's Horizon 2020 research and innovation programme (MARSU (grant no. 690958)) and the German Research Foundation (PHOSDMAP (grant no. GZ: FO1106/2-1)).

The publication of this article was funded by the Open Access Fund of the Leibniz Association.

Review statement. This paper was edited by Pierre Herckes and reviewed by Semia Cherif, Weijun $\mathrm{Li}$, and one anonymous referee.

\section{References}

Bennun, L. and Sanhueza, V.: A Procedure for the Improvement in the Determination of a TXRF Spectrometer Sensitivity Curve, Anal. Sci., 26, 331-335, https://doi.org/10.2116/analsci.26.331, 2010.

Bertin, E. P.: Principles and practice of Quantitative X-ray Flourescence Analysis, 2nd ed., Plenum Press, New York, USA, 1975.

Bianco, A., Vaitilingom, M., Bridoux, M., Chaumerliac, N., Pichon, J. M., Piro, J. L., and Deguillaume, L.: Trace Metals in Cloud Water Sampled at the Puy De Dome Station, Atmosphere-Basel, 8, 225, https://doi.org/10.3390/atmos8110225, 2017.

Bilo, F., Borgese, L., Cazzago, D., Zacco, A., Bontempi, E., Guarneri, R., Bernardello, M., Attuati, S., Lazo, P., and Depero, L. E.: TXRF analysis of soils and sediments to assess environmental contamination, Environ. Sci. Pollut. R., 21, 1320813214, https://doi.org/10.1007/s11356-013-2203-y, 2014.

Bilo, F., Borgese, L., Wambui, A., Assi, A., Zacco, A., Federici, S., Eichert, D. M., Tsuji, K., Lucchini, R. G., Placidi, D., Bontempi, E., and Depero, L. E.: Comparison of multiple Xray fluorescence techniques for elemental analysis of particulate matter collected on air filters, J. Aerosol Sci., 122, 1-10, https://doi.org/10.1016/j.jaerosci.2018.05.003, 2018.

Buck, C. S. and Paytan, A.: Evaluation of commonly used filter substrates for the measurement of aerosol trace element solubility, Limnol Oceanogr.-Meth., 10, 790-806, https://doi.org/10.4319/lom.2012.10.790, 2012.

Buck, C. S., Aguilar-Islas, A., Marsay, C., Kadko, D., and Landing, W. M.: Trace element concentrations, elemental ratios, and enrichment factors observed in aerosol samples collected during the US GEOTRACES eastern Pacific Ocean transect (GP16), Chem. Geol., 511, 212-224, https://doi.org/10.1016/j.chemgeo.2019.01.002, 2019.

Cardoso, J., Almeida, S. M., Nunes, T., Almeida-Silva, M., Cerqueira, M., Alves, C., Rocha, F., Chaves, P., Reis, M., Salvador, P., Artiñano, B., and Pio, C.: Source apportionment of atmospheric aerosol in a marine dusty environment by ionic/composition mass balance (IMB), Atmos. Chem. Phys., 18, 13215-13230, https://doi.org/10.5194/acp-18-13215-2018, 2018.
Cheng, Z. L., Lam, K. S., Chan, L. Y., Wang, T., and Cheng, K. K.: Chemical characteristics of aerosols at coastal station in Hong Kong. I. Seasonal variation of major ions, halogens and mineral dusts between 1995 and 1996, Atmos. Environ., 34, 2771-2783, https://doi.org/10.1016/S1352-2310(99)00343-X, 2000.

Cherif, S., Millet, M., Sanusi, A., Herckes, P., and Wortham, H.: Protocol for analysis of trace metals and other ions in filtered and unfiltered fogwater, Environ. Pollut., 103, 301-308, https://doi.org/10.1016/S0269-7491(98)00108-0, 1998.

Cho, K. and Wu, C. Y.: Control of molybdenum emission by sorbents: Equilibrium analysis, J. Environ. Eng., 130, 201204, https://doi.org/10.1061/(Asce)0733-9372(2004)130:2(201), 2004.

Cullen, J. T. and Sherrell, R. M.: Techniques for determination of trace metals in small samples of size-fractionated particulate matter: phytoplankton metals off central California, Mar. Chem., 67, 233-247, https://doi.org/10.1016/S0304-4203(99)00060-2, 1999.

De La Calle, I., Cabaleiro, N., Romero, V., Lavilla, I., and Bendicho, C.: Sample pretreatment strategies for total reflection X-ray fluorescence analysis: A tutorial review, Spectrochim. Acta B, 90, 23-54, https://doi.org/10.1016/j.sab.2013.10.001, 2013.

Deguillaume, L., Leriche, M., Desboeufs, K., Mailhot, G., George, C., and Chaumerliac, N.: Transition metals in atmospheric liquid phases: Sources, reactivity, and sensitive parameters, Chem. Rev., 105, 3388-3431, https://doi.org/10.1021/Cr040649c, 2005.

Dehghani, S., Moore, F., Vasiluk, L., and Hale, B. A.: The geochemical fingerprinting of geogenic particles in road deposited dust from Tehran metropolis, Iran: Implications for provenance tracking, J. Geochem. Explor., 190, 411-423, https://doi.org/10.1016/j.gexplo.2018.04.011, 2018.

Demoz, B. B., Collett, J. L., and Daube, B. C.: On the Caltech Active Strand Cloudwater Collectors, Atmos. Res., 41, 47-62, https://doi.org/10.1016/0169-8095(95)00044-5, 1996.

Dhara, S., Misra, N. L., Thakur, U. K., Shah, D., Sawant, R. M., Ramakumar, K. L., and Aggarwal, S. K.: A total reflection X-ray fluorescence method for the determination of chlorine at trace levels in nuclear materials without sample dissolution, X-Ray Spectrom., 41, 316-320, https://doi.org/10.1002/xrs.2400, 2012.

Ervens, B.: Modeling the Processing of Aerosol and Trace Gases in Clouds and Fogs, Chem. Rev., 115, 4157-4198, https://doi.org/10.1021/cr5005887, 2015.

Fomba, K. W., van Pinxteren, D., Müller, K., Iinuma, Y., Lee, T., Collett Jr., J. L., and Herrmann, H.: Trace metal characterization of aerosol particles and cloud water during HCCT 2010, Atmos. Chem. Phys., 15, 8751-8765, https://doi.org/10.5194/acp15-8751-2015, 2015.

Font, A., de Hoogh, K., Leal-Sanchez, M., Ashworth, D. C., Brown, R. J. C., Hansell, A. L., and Fuller, G. W.: Using metal ratios to detect emissions from municipal waste incinerators in ambient air pollution data, Atmos. Environ., 113, 177-186, https://doi.org/10.1016/j.atmosenv.2015.05.002, 2015.

Harris, E., Sinha, B., van Pinxteren, D., Tilgner, A., Fomba, K. W., Schneider, J., Roth, A., Gnauk, T., Fahlbusch, B., Mertes, S., Lee, T., Collett, J., Foley, S., Borrmann, S., Hoppe, P., and Herrmann, H.: Enhanced Role of Transition Metal Ion Catalysis During In-Cloud Oxidation of SO2, Science, 340, 727-730, https://doi.org/10.1126/science.1230911, 2013. 
Harrison, R. M., Jones, A. M., Gietl, J., Yin, J. X., and Green, D. C.: Estimation of the Contributions of Brake Dust, Tire Wear, and Resuspension to Nonexhaust Traffic Particles Derived from Atmospheric Measurements, Environ. Sci. Technol., 46, 65236529, https://doi.org/10.1021/es300894r, 2012.

He, M. C., Wang, X. Q., Wu, F. C., and Fu, Z. Y.: Antimony pollution in China, Sci. Total Environ., 421, 41-50, https://doi.org/10.1016/j.scitotenv.2011.06.009, 2012.

Herrmann, H., Schaefer, T., Tilgner, A., Styler, S. A., Weller, C., Teich, M., and Otto, T.: Tropospheric Aqueous-Phase Chemistry: Kinetics, Mechanisms, and Its Coupling to a Changing Gas Phase, Chem. Rev., 115, 4259-4334, https://doi.org/10.1021/cr500447k, 2015.

Hutchings, J. W., Robinson, M. S., McIlwraith, H., Triplett Kingston, J., and Herckes, P.: The Chemistry of Intercepted Clouds in Northern Arizona during the North American Monsoon Season, Water Air Soil Poll. 199, 191-202, https://doi.org/10.1007/s11270-008-9871-0, 2009.

Itoh, A., Oshiro, Y., Azechi, S., Somada, Y., Handa, D., Miyagi, Y., Nakano, K., Tanahara, A., and Arakaki, T.: Long-term Monitoring of Metal Elements in Total Suspended Particle Aerosols Simultaneously Collected at Three Islands in Okinawa, Japan, Asian Journal of Atmospheric Environment, 12, 326-337, https://doi.org/10.5572/ajae.2018.12.4.326, 2018.

Kchih, H., Perrino, C., and Cherif, S.: Investigation of Desert Dust Contribution to Source Apportionment of $\mathrm{PM}_{10}$ and PM2.5 from a Southern Mediterranean Coast, Aerosol Air. Qual. Res., 15, 454-464, https://doi.org/10.4209/aaqr.2014.10.0255, 2015.

Klockenkämper, R. and von Bohlen, A.: Worldwide distribution of Total Reflection X-ray Fluorescence instrumentation and its different fields of application: A survey, Spectrochim. Acta B, 99, 133-137, https://doi.org/10.1016/j.sab.2014.06.010, 2014a.

Klockenkämper, R. and von Bohlen, A.: Principles of Total Reflection XRF, in: Total-Reflection X-Ray Fluorescence Analysis and Related Methods, John Wiley \& Sons, Hoboken, New Jersey, 79125, https://doi.org/10.1002/9781118985953.ch02, 2014b.

Li, W. J., Wang, Y., Collett, J. L., Chen, J. M., Zhang, X. Y., Wang, Z. F., and Wang, W. X.: Microscopic Evaluation of Trace Metals in Cloud Droplets in an Acid Precipitation Region (vol. 47, pg. 4172, 2013), Environ. Sci. Technol., 47, 6067-6067, https://doi.org/10.1021/Es402145c, 2013.

Li, T., Wang, Y., Zhou, J., Wang, T., Ding, A. J., Nie, W., Xue, L. K., Wang, X. F., and Wang, W. X.: Evolution of trace elements in the planetary boundary layer in southern China: Effects of dust storms and aerosol-cloud interactions, J. Geophys. Res.-Atmos., 122, 3492-3506, https://doi.org/10.1002/2016jd025541, 2017.

Liu, X. H., Wai, K. M., Wang, Y., Zhou, J., Li, P. H., Guo, J., Xu, P. J., and Wang, W. X.: Evaluation of trace elements contamination in cloud/fog water at an elevated mountain site in Northern China, Chemosphere, 88, 531-541, https://doi.org/10.1016/j.chemosphere.2012.02.015, 2012.

Losno, R.: Trace metals acting as catalysts in a marine cloud: a box model study, Phys. Chem. Earth Pt. B, 24, 281-286, https://doi.org/10.1016/S1464-1909(98)00051-3, 1999.

Ma, C. J., Tohno, S., Kasahara, M., and Hayakawa, S.: Determination of the chemical properties of residues retained in individual cloud droplets by XRF microprobe at SPring-8, Nucl. Instrum. Meth. B, 217, 657-665, https://doi.org/10.1016/j.nimb.2003.12.042, 2004.
Milando, C., Huang, L., and Batterman, S.: Trends in PM2.5 emissions, concentrations and apportionments in Detroit and Chicago, Atmos. Environ., 129, 197-209, https://doi.org/10.1016/j.atmosenv.2016.01.012, 2016.

Miller, A. J., Raduma, D. M., George, L. A., and Fry, J. L.: Source apportionment of trace elements and black carbon in an urban industrial area (Portland, Oregon), Atmos. Pollut. Res., 10, 784 794, https://doi.org/10.1016/j.apr.2018.12.006, 2019.

Motellier, S., Lhaute, K., Guiot, A., Golanski, L., Geoffroy, C., and Tardif, F.: Direct quantification of airborne nanoparticles composition by TXRF after collection on filters, J. Phys. Conf. Ser., 304, 012009, https://doi.org/10.1088/1742-6596/304/1/012009, 2011.

Okuda, T., Fujimori, E., Hatoya, K., Takada, H., Kumata, H., Nakajima, F., Hatakeyama, S., Uchida, M., Tanaka, S., He, K. B., Ma, Y. L., and Haraguchi, H.: Rapid and Simple Determination of Multi-Elements in Aerosol Samples Collected on Quartz Fiber Filters by Using EDXRF Coupled with Fundamental Parameter Quantification Technique, Aerosol Air Qual. Res., 13, 1864 1876, https://doi.org/10.4209/aaqr.2012.11.0308, 2013.

Pacyna, E. G., Pacyna, J. M., Fudala, J., Strzelecka-Jastrzab, E., Hlawiczka, S., Panasiuk, D., Nitter, S., Pregger, T., Pfeiffer, H., and Friedrich, R.: Current and future emissions of selected heavy metals to the atmosphere from anthropogenic sources in Europe, Atmos. Environ., 41, 8557-8566, https://doi.org/10.1016/j.atmosenv.2007.07.040, 2007.

Pan, Y. P., Wang, Y. S., Sun, Y., Tian, S. L., and Cheng, M. T.: Size-resolved aerosol trace elements at a rural mountainous site in Northern China: Importance of regional transport, Sci. Total Environ., 461, 761-771, https://doi.org/10.1016/j.scitotenv.2013.04.065, 2013.

Pant, P., and Harrison, R. M.: Estimation of the contribution of road traffic emissions to particulate matter concentrations from field measurements: A review, Atmos. Environ., 77, 78-97, https://doi.org/10.1016/j.atmosenv.2013.04.028, 2013.

Passananti, M., Vinatier, V., Delort, A. M., Mailhot, G., and Brigante, M.: Siderophores in Cloud Waters and Potential Impact on Atmospheric Chemistry: Photoreactivity of Iron Complexes under Sun-Simulated Conditions, Environ. Sci. Technol., 50, 9324 9332, https://doi.org/10.1021/acs.est.6b02338, 2016.

Patey, M. D., Achterberg, E. P., Rijkenberg, M. J., and Pearce, R.: Aerosol time-series measurements over the tropical Northeast Atlantic Ocean: Dust sources, elemental composition and mineralogy, Mar. Chem., 174, 103-119, https://doi.org/10.1016/j.marchem.2015.06.004, 2015.

Prost, J., Wobrauschek, P., and Streli, C.: Quantitative total reflection X-ray fluorescence analysis of directly collected aerosol samples, X-Ray Spectrom., 46, 454-460, https://doi.org/10.1002/xrs.2752, 2017.

Shelley, R. U., Morton, P. L., and Landing, W. M.: Elemental ratios and enrichment factors in aerosols from the US-GEOTRMES North Atlantic transects, Deep-Sea Res. Pt. II, 116, 262-272, https://doi.org/10.1016/j.dsr2.2014.12.005, 2015.

Steinhoff, G., Haupt, O., and Dannecker, W.: Fast determination of trace elements on aerosol-loaded filters by $\mathrm{X}$ ray fluorescence analysis considering the inhomogeneous elemental distribution, Fresen. J. Anal. Chem., 366, 174-177, https://doi.org/10.1007/s002160050034, 2000. 
Stosnach, H.: Environmental trace-element analysis using a benchtop total reflection X-ray, fluorescence spectrometer, Anal. Sci., 21, 873-876, https://doi.org/10.2116/analsci.21.873, 2005.

Tian, H. Z., Zhou, J. R., Zhu, C. Y., Zhao, D., Gao, J. J., Hao, J. M., He, M. C., Liu, K. Y., Wang, K., and Hua, S. B.: A Comprehensive Global Inventory of Atmospheric Antimony Emissions from Anthropogenic Activities, 1995-2010, Environ. Sci. Technol., 48, 10235-10241, https://doi.org/10.1021/es405817u, 2014.

Towett, E. K., Shepherd, K. D., and Cadisch, G.: Quantification of total element concentrations in soils using total X-ray fluorescence spectroscopy (TXRF), Sci. Total Environ., 463, 374-388, https://doi.org/10.1016/j.scitotenv.2013.05.068, 2013.

Upadhyay, N., Majestic, B. J., Prapaipong, P., and Herckes, P.: Evaluation of polyurethane foam, polypropylene, quartz fiber, and cellulose substrates for multi-element analysis of atmospheric particulate matter by ICP-MS, Anal. Bioanal. Chem., 394, 255266, https://doi.org/10.1007/s00216-009-2671-6, 2009.

van Pinxteren, D., Fomba, K. W., Spindler, G., Muller, K., Poulain, L., Iinuma, Y., Loschau, G., Hausmann, A., and Herrmann, H.: Regional air quality in Leipzig, Germany: detailed source apportionment of size-resolved aerosol particles and comparison with the year 2000, Faraday Discuss., 189, 291-315, https://doi.org/10.1039/c5fd00228a, 2016.

VanCuren, R. A., Cahill, T., Burkhart, J., Barnes, D., Zhao, Y. J., Perry, K., Cliff, S., and McConnell, J.: Aerosols and their sources at Summit Greenland - First results of continuous size- and time-resolved sampling, Atmos. Environ., 52, 82-97, https://doi.org/10.1016/j.atmosenv.2011.10.047, 2012.

Venter, A. D., van Zyl, P. G., Beukes, J. P., Josipovic, M., Hendriks, J., Vakkari, V., and Laakso, L.: Atmospheric trace metals measured at a regional background site (Welgegund) in South Africa, Atmos. Chem. Phys., 17, 4251-4263, https://doi.org/10.5194/acp-17-4251-2017, 2017.

Vlastelic, I., Suchorski, K., Sellegri, K., Colomb, A., Nauret, F., Bouvier, L., and Piro, J. L.: The trace metal signature of atmospheric aerosols sampled at a European regional background site (puy de Dme, France), J Atmos Chem, 71, 195-212, https://doi.org/10.1007/s10874-014-9290-0, 2014.

von Bohlen, A. and Fernández-Ruiz, R.: Experimental evidence of matrix effects in total-reflection X-ray fluorescence analysis: Coke case, Talanta, 209, 120562, https://doi.org/10.1016/j.talanta.2019.120562, 2020.
Wagner, A., and Mages, M.: Total-Reflection X-ray fluorescence analysis of elements in size-fractionated particulate matter sampled on polycarbonate filters - Composition and sources of aerosol particles in Goteborg, Sweden, Spectrochim. Acta B, 65, 471-477, https://doi.org/10.1016/j.sab.2010.02.007, 2010.

Wedepohl, K. H.: The Composition of the Continental-Crust, Geochim. Cosmochim. Ac., 59, 1217-1232, 1995.

Weller, R., Woltjen, J., Piel, C., Resenberg, R., Wagenbach, D., Konig-Langlo, G., and Kriews, M.: Seasonal variability of crustal and marine trace elements in the aerosol at Neumayer station, Antarctica, Tellus B, 60, 742-752, https://doi.org/10.1111/j.1600-0889.2008.00372.x, 2008.

Woelfl, S., Mages, M., and Encina, F.: Cold plasma ashing improves the trace element detection of single Daphnia specimens by total reflection X-ray fluorescence spectrometry, Spectrochim. Acta B, 58, 2157-2168, https://doi.org/10.1016/S05848547(03)00196-4, 2003.

Xu, X. M., Chen, J. M., Zhu, C., Li, J. R., Sui, X., Liu, L., and Sun, J. F.: Fog composition along the Yangtze River basin: Detecting emission sources of pollutants in fog water, J. Environ Sci.-China, 71, 2-12, https://doi.org/10.1016/j.jes.2017.09.018, 2018.

Zhang, R., Cao, J. J., Tang, Y. R., Arimoto, R., Shen, Z. X., Wu, F., Han, Y. M., Wang, G. H., Zhang, J. Q., and Li, G. H.: Elemental profiles and signatures of fugitive dusts from Chinese deserts, Sci. Total Environ., 472, 1121-1129, https://doi.org/10.1016/j.scitotenv.2013.11.011, 2014.

Zhao, J. H., Yan, X., Zhou, T. Y., Wang, J., Li, H. Y., Zhang, P., Ding, H., and Ding, L.: Multi-throughput dynamic microwave-assisted leaching coupled with inductively coupled plasma atomic emission spectrometry for heavy metal analysis in soil, J. Anal. Atom. Spectrom., 30, 1920-1926, https://doi.org/10.1039/c5ja00233h, 2015.

Zhu, C., Tian, H., and Hao, J.: Global anthropogenic atmospheric emission inventory of twelve typical hazardous trace elements, 1995-2012, Atmos. Environ., 220, 117061, https://doi.org/10.1016/j.atmosenv.2019.117061, 2019. 